\title{
Avaliação do potencial gerador de petróleo da seção Aptiana-Albiana da Bacia de Sergipe, integrando análises palinofaciológicas e dados de geoquímica orgânica
}

\author{
Evaluation of the potential generator Aptian-Albian oil section of the
} Sergipe Basin, integrating palynofacies and organic geochemistry analyses

\author{
Ana Cristina Meirelles Quintanilha Coelho ${ }^{1 *}$, Luzia Antonioli ${ }^{2}$, Rodolfo Dino ${ }^{3}$, \\ Helena Antunes Portela ${ }^{4}$
}

RESUMO: Os dados apresentados neste trabalho referem-se aos estudos integrando análises palinofaciológicas e de geoquímica orgânica, que foram realizados em 51 amostras de testemunho do poço 9-PEC-41-SE, localizado na Bacia de Sergipe na margem leste continental brasileira. Buscou-se avaliar o potencial de geração de petróleo, identificando o tipo e o grau de maturação da matéria orgânica das rochas geradoras da seção. As análises ópticas mostram que o material orgânico é composto, em maior proporção, por matéria orgânica amorfa em bom estado de preservaçáo com alta fluorescência. Apresenta uma média de $67 \%$ em relação à composição total do querogênio. Os fitoclastos, geralmente, apresentam-se bem preservados em praticamente toda a seçăo. Os palinomorfos são constituídos por uma associaçăo composta predominantemente por esporos e grãos de pólen do gênero Classopollis, o que caracteriza um ambiente com clima predominantemente árido a semiárido para a época de deposiçáo. A presença de dinoflagelado na porção superior da seção evidencia as primeiras ingressốes marinhas ocorridas no final do Aptiano. Baseando-se nos resultados qualitativos e quantitativos do querogênio foi possível caracterizar três palinofácies distintas, a palinofácies I apresentou as melhores características de qualidade e preservaçẫo do material orgânico. Os resultados do carbono orgânico total mostram valores de até 6,39\%, e os dados de pirólise Rock-Eval apontaram para o querogênio do tipo II rico em matéria orgânica adequados para a formação de acumulaçóes dos hidrocarbonetos. $\mathrm{O}$ índice de hidrogênio encontra-se entre 200 e $550 \mathrm{mg} \mathrm{HC} / \mathrm{g}$ de carbono orgânico total, o que demonstra o bom potencial de geração para óleo e gás. Os dados do índice de coloração de esporos mostram que o material orgânico encontra-se predominantemente na fase de maturação imatura, com valor de ICE 4,0 a 4,5, corroborando aqueles de temperatura máxima, de até $432^{\circ} \mathrm{C}$.

PALAVRAS-CHAVE: Bacia de Sergipe; geoquímica orgânica; palinofácies; geologia do petróleo; hidrocarbonetos.
ABSTRACT: Data presented in this investigation refer to studies integrating palynofacies and organic geochemistry analyses that were performed on 51 samples of PEC-41-SE-9 well, located in the Sergipe Basin, Eastern Brazilian continental margin. It was evaluated the potential for oil generation, identifying the type and degree of maturation of the organic matter. Optical analyzes show that the organic matter is composed in greater proportion by amorphous organic matter in good preservation, with high fluorescence. It also presents a $67 \%$ average concerning the total composition of the kerogen. The phytoclasts usually are well preserved in almost all the section. The palynomorphs are composed of an association, predominantly, of spores and pollen grains of genus Classopollis, featuring a predominantly arid to semi-arid climate environment at deposition time. Presence of the dinoflagellate in the upper section displays the first marine ingressions that happened in the end of Aptian. Based on the qualitative and quantitative results of kerogen, it was possible to characterize three distinct palynofacies, in which the palynofacies I had the best features for quality and preservation of organic matter. The results show total organic carbon values up to $6.39 \%$ and Rock-Eval pyrolysis data pointed to the type II kerogen rich in organic matter suitable for the formation of hydrocarbon accumulations. The hydrogen index is found between 200 and $550 \mathrm{mg} \mathrm{HClg}$ of total organic carbon, which shows good potential for oil and gas generation. Spore color index data conclude that the organic matter is found predominantly on the immature maturation phase, with SCI values of 4.0 to 4.5, corroborating with data of maximum temperature, of up to $432^{\circ} \mathrm{C}$.

KEYWORDS: Sergipe Basin; organic geochemistry; petrography; palynofacies; petroleum geology; hydrocarbons.

\footnotetext{
${ }^{1}$ Programa de Pós-Graduação em Análise de Bacias e Faixas Móveis, Faculdade de Geologia, Universidade do Estado do Rio de Janeiro - UERJ, Rio de Janeiro (RJ), Brasil. E-mail: anacoelho.ep@gmail.com

${ }^{2}$ Faculdade de Geologia, Universidade do Estado do Rio de Janeiro - UERJ, Rio de Janeiro (RJ), Brasil. E-mail: luantonioli@ig.com.br

${ }^{3}$ Faculdade de Geologia, Universidade do Estado do Rio de Janeiro - UERJ; Petrobras - Centro de Pesquisas e Desenvolvimento Leopoldo Américo Miguez de Melo, Pesquisa em Desenvolvimento em Gás, Energia e Desenvolvimento Sustentado, Rio de Janeiro (RJ), Brasil. E-mail: dino@petrobras.com.br

${ }^{4}$ Faculdade de Formação de Professores, Universidade do Estado do Rio de Janeiro - UERJ, Rio de Janeiro (RJ), Brasil. E-mail: helenaportela@gmail.com

*Autor correspondente

Manuscrito ID: 30089. Recebido em: 24/02/2014. Aprovado em: 31/10/2014.
} 


\section{INTRODUÇÃO}

Este trabalho refere-se à avaliação do potencial de geração de hidrocarbonetos de uma seção Cretácea da Bacia de Sergipe, utilizando dados de geoquímica e métodos palinofaciológicos. As análises incluíram: verificação do estado de preservação da matéria orgânica amorfa; caracterização das diferentes palinofácies e tipos de materiais orgânicos; determinação dos valores percentuais de carbono orgânico total (COT); obtenção dos valores de pirólise Rock-Evale do índice de maturação térmica (ICE); determinação do tipo de querogênio (I, II, III ou IV); identificação da qualidade, evolução térmica e potencial gerador de petróleo da matéria orgânica e identificação das associaçóes palinoflorísticas presentes no material.

A integração das ferramentas da geoquímica orgânica e de palinofácies, possibilita a caracterização das rochas geradoras de hidrocarbonetos, as quais são capazes de gerar e expulsar hidrocarbonetos em quantidades suficientes para formar acumulaçóes de óleo ou gás (Hunt, 1995).

A seção Aptiana-Albiana estudada está inserida no contexto da Bacia de Sergipe, que é correlata com as demais bacias petrolíferas do Brasil.

As rochas selecionadas para a pesquisa pertencem, predominantemente, aos três membros da Formação Muribeca (Carmopólis, Ibura e Oiteirinhos) inseridos no sistema petrolífero Muribeca, que possui como rocha geradora de hidrocarbonetos os folhelhos pretos Aptianos do Membro Ibura.

A Bacia de Sergipe está em um estágio avançado quanto às pesquisas exploratórias, devido aos estudos intensos voltados para a exploração de hidrocarbonetos, tanto no domínio onshore como no offshore. No entanto, tais informaçôes são pouco divulgadas na literatura científica e, em especial, as pesquisas utilizando como ferramenta a geoquímica orgânica e as análises de palinofácies.

A caracterização das rochas geradoras de petróleo constitui uma informação essencial para a avaliação dos riscos que envolvem a exploração petrolífera, principalmente em bacias maduras, como é o caso da Bacia de Sergipe.

\section{CONTEXTO GEOLÓGICO REGIONAL}

A Bacia de Sergipe-Alagoas está situada na margem leste continental brasileira e possui aproximadamente $350 \mathrm{~km}$ de extensão paralela à costa, ocupando uma faixa litorânea alongada NE-SW, que abrange uma área de $45.760 \mathrm{~km}^{2}$, nos respectivos estados, incluindo as porçóes emersa e submersa (Aquino \& Lana 1990).

A Bacia registra a sucessão estratigráfica mais completa dentre todas as bacias da margem continental brasileira, compreendidas pelas megassequências: pré-rifte, rifte, transicional e pós-rifte (Cainelli \& Mohriak 1998).

A deposição na Bacia de Sergipe iniciou-se no Permocarbonífero, no final do Paleozoico, com a fase de sinéclise interior, que se manteve até o final do Jurássico, incluindo também o início do Cretáceo (Neocomiano), gerando um registro sedimentar caracterizado por sedimentos de origem continental.

A partir do Neocomiano (Hauteriviano), começou a sofrer os reflexos da abertura do Oceano Atlântico, desenvolvendo a fase rifte até a metade do Aptiano, quando passou a ter um caráter transicional e no final do Aptiano até o recente, evoluiu para uma bacia do tipo margem passiva.

O intervalo analisado neste trabalho está inserido no contexto transicional que representa a passagem de ambiente continental para marinho sob severas condiçóes de restrição e aridez. Corresponde predominantemente à seção de idade Aptiana-Albiana, que abrange litoestratigraficamente a Formação Muribeca e uma porção da base pertencente à Formação Riachuelo.

A sedimentação Aptiana-Albiana ocorreu em ambientes de leques aluviais e deltaicos em corpo de água restrito. A seção Aptiana é representada pela Formação Muribeca, que se iniciou com deposição de conglomerados e arenitos (Membro Carmópolis), os quais são os principais reservatórios da Bacia, seguida pela deposição dos folhelhos negros, calcilutitos e evaporitos dos Membros Oiterinhos e Ibura, os quais representam a principal rocha geradora da Bacia. A seção Albiana pertence à Formação Riachuelo, composta por sedimentos marinhos (Membro Angico) e depósitos lagunares do Membro Taquari.

\section{MATERIAIS E MÉTODOS}

As amostras analisadas foram obtidas em testemunho contínuo do poço 9-PEC-41-SE, em furo de sondagem de 387,9 $\mathrm{m}$ de profundidade, realizada pela PETROMISA (Petrobras Mineração S.A) no campo produtor onshore de Siririzinho, no Estado do Sergipe.

A metodologia baseou-se na avaliação dos dados palinofaciológicos e de geoquímica orgânica para determinar as rochas potencialmente geradoras de petróleo.

As rochas presentes no poço correspondem a folhelhos, siltitos, arenitos, calcarenitos, calcilutitos, dolomitos, conglomerados, margas, calcário cristalino e anidrita nodular correspondente ao ciclo evaporítico Ibura (Szatmari 1980).

Baseando-se nas características litológicas, foram selecionadas 51 amostras (Fig. 1) para a análise de porcentagem do COT. A partir dos resultados obtidos acima de 1\% de COT, foram selecionadas 43 amostras para análise da 
pirólise Rock-Eval e 26 para preparação das lâminas organopalinológicas e palinológicas em intervalos de 3 em $3 \mathrm{~m}$, preferencialmente.

As análises ópticas das lâminas organopalinológicas e palinológicas foram realizadas utilizando microscopia de luz branca transmitida e fluorescência.

\section{Métodos petrográficos}

O processamento físico-químico das amostras para a caracterização palinológica e palinofaciológica utilizou técnicas de processamento palinológico descritas por Combaz (1964; 1980), Uesugui (1979), Dettmann (1963), Phipps e Playford (1984), Tyson (1995) e Wood et al. (1996), aplicadas para obtenção do querogênio concentrado, sendo utilizadas por laboratórios de palinologia em todo o mundo, conforme ilustrado no fluxograma das etapas de preparação das lâminas palinológicas e palinofaciológicas (Fig. 2).

As análises palinofaciológicas (Fig. 3) foram realizadas no resíduo orgânico total da amostra de rocha para definir os constituintes orgânicos contidos no sedimento após a remoção da matriz sedimentar mineral, por meio dos processos

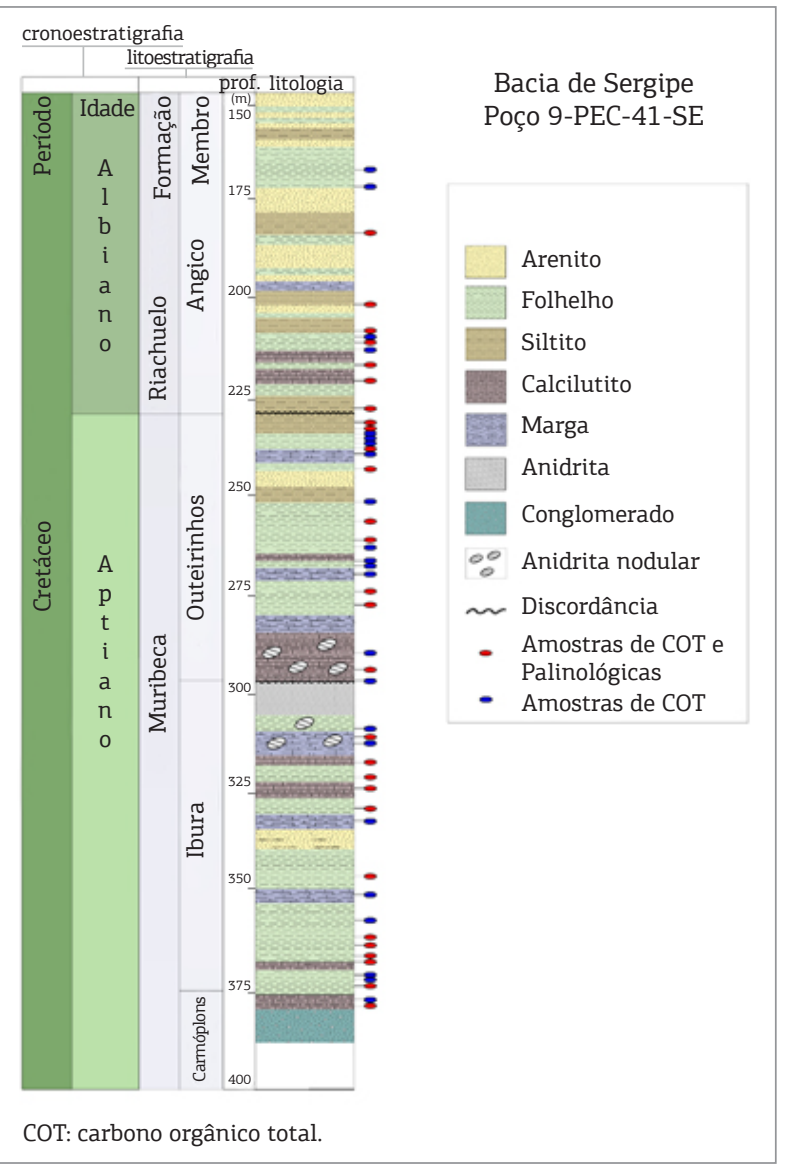

Figura 1. Perfil litológico da seção estudada no poço 9-PEC-41-SE com as amostras selecionadas para as análises palinológicas e de carbono orgânico total. de acidificação com ácidos clorídrico $(\mathrm{HCl})$ e fluorídrico HF (Mendonça Filho et al. 2009).

A integração das técnicas de microscopia e geoquímica orgânica é utilizada para entender os processos que envolvem a produção, a distribuição, a decomposição e a preservação da matéria orgânica sedimentar (Tyson 1995; Mendonça Filho 1999; Mendonça Filho et al. 2001).

O querogênio foi classificado por meio das propriedades ópticas, considerando forma, estrutura, cor e intensidade de fluorescência do constituinte orgânico.

As análises quantitativas dos constituintes do querogênio foram realizadas para definir e caracterizar as palinofácies. Nesta classificação, os dados percentuais relativos das partículas foram obtidos pela contagem de até 300 partículas com dimensôes superiores a $10 \mu \mathrm{m}$ (Tyson 1995; Mendonça Filho 1999).

$\mathrm{Na}$ avaliação do material, foi possível identificar e quantificar os três principais grupos de constituintes que compóem o querogênio: os fitoclastos, os palinomorfos e a matéria orgânica amorfa (Fig. 4).

Os resultados da contagem foram representados em gráficos e tabelas e, posteriormente, integrados com os dados geoquímicos obtidos nos resultados de COT, enxofre total e resíduo insolúvel. A representação gráfica foi elaborada com a utilização do programa Grapher, versão 4.0 para Windows, utilizando-se o valor percentual para cada um dos componentes orgânicos obtidos. Isso resultou em gráficos lineares, que permitiram a visualização dos grupos de querogênio e a individualização das palinofácies.

O método para avaliar a qualidade da matéria orgânica utilizado para caracterizar os níveis de preservação do constituinte orgânico amorfo e dos palinomorfos foi obtido por meio de análises ópticas de fluorescência. Segundo Tyson (1995), as mais intensas fluorescências ocorrem no querogênio liptínico gerador de óleo, originado em ambiente deposicional, com alto potencial de preservação.

As fluorescências mais fracas ou ausentes correspondem aos componentes orgânicos de composição química aromática, que não possuem bom potencial para geração de hidrocarbonetos.

As análises de cor e intensidade da fluorescência permitem determinar o estado de preservação da matéria orgânica e definir o potencial gerador da rocha.

A identificação dos tipos de querogênio permite diferenciar o potencial de geração de uma rocha.

A avaliação dos diferentes tipos e da preservação da matéria orgânica é realizada com o microscópio óptico em luz branca transmitida e fluorescência (Tyson 1995), relacionando o estado de preservação da matéria orgânica ao potencial de geração dos hidrocarbonetos. 


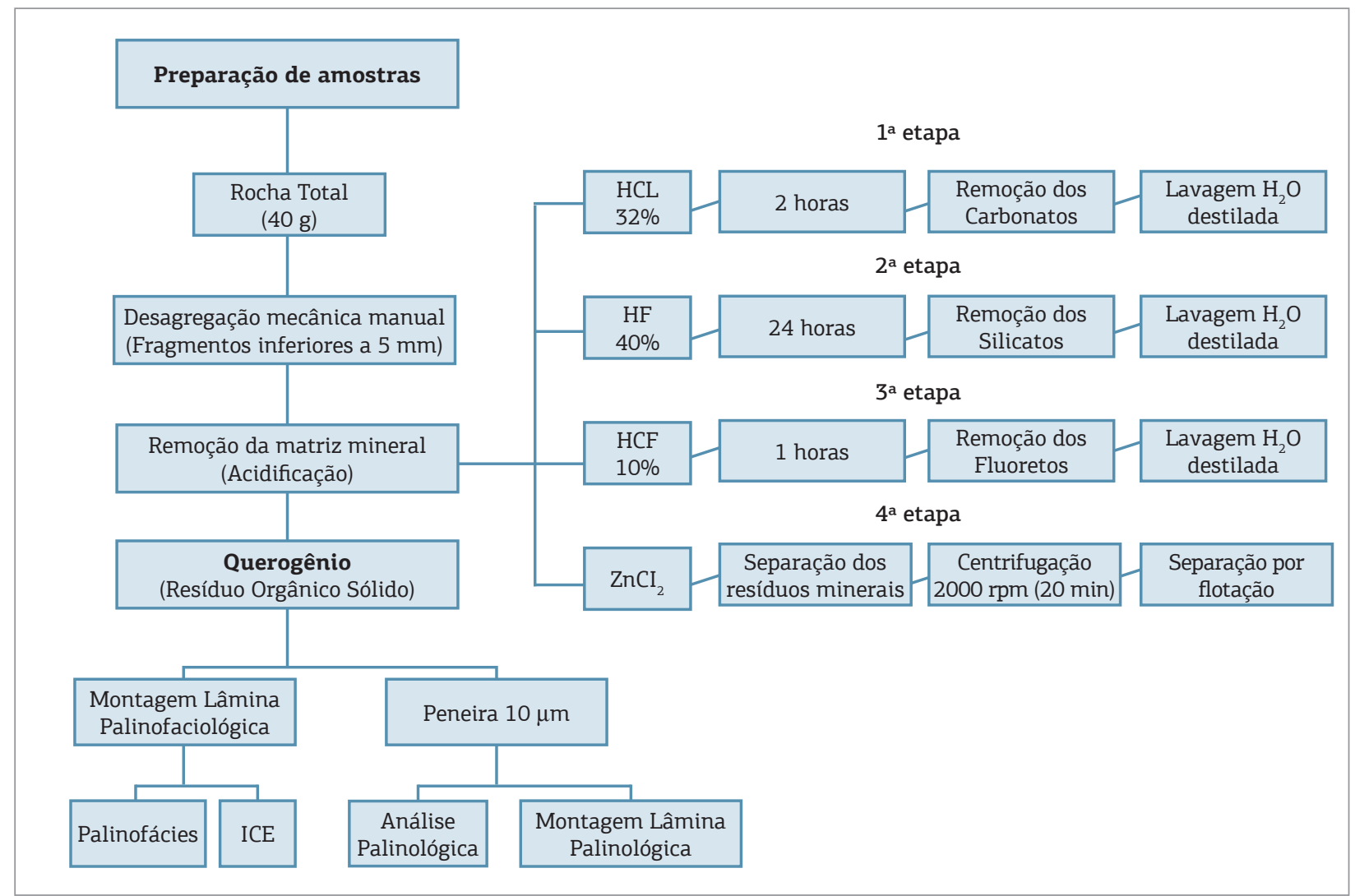

Figura 2. Fluxograma das etapas de preparação das amostras para análises palinológicas e palinofaciológicas, segundo a metodologia de Tyson (1995).

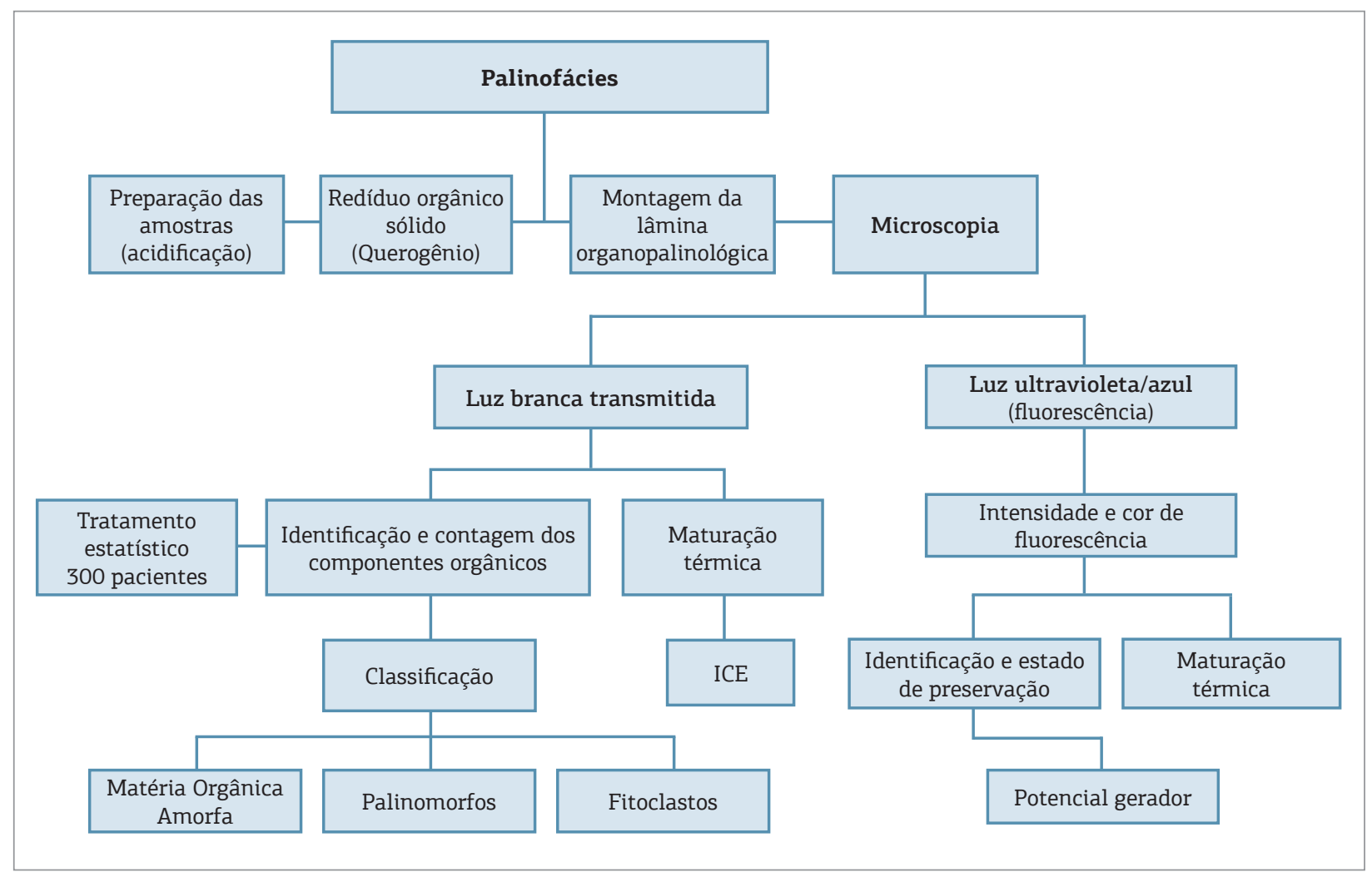

Figura 3. Fluxograma de etapas das análises de palinofácies, segundo a metodologia de Tyson (1995). 
A análise palinológica é aplicada para a identificação e individualização dos grupos de palinomorfos, tanto de origem alóctone, representado pelos esporos e grãos de pólen, como os componentes autóctones.

Para a análise palinológica, o microscópio óptico foi empregado para identificar as espécies, seguido da pesquisa bibliográfica para identificar o morfotipo encontrado e classificá-lo.

A análise da maturação térmica da matéria orgânica foi usada por meio do ICE, desenvolvido por Barnard et al. (1981), que permite atribuir valores numéricos, em escala de 1 a 10 , para as variaçóes de cor ocorridas nos esporomorfos (esporos e grãos de pólen). De acordo com o aumento da profundidade e temperatura, as cores variam de amarelo-claro, em baixas temperaturas, até preto, em altas.

A coloração dos componentes orgânicos é alterada de sua cor original, quando submetida ao aumento de temperaturas, ficando mais escura à medida que a temperatura se eleva (carbonização).

A determinação do ICE foi realizada nas lâminas organofaciológicas, utilizando a microscopia óptica de luz branca transmitida, baseada na tabela de lâminas padrão da Robertson Research International Limited (Tyson 1995).

\section{Métodos de geoquímica orgânica}

A evolução térmica da matéria orgânica foi analisada integrando os dados de COT e pirólise Rock-Eval, que permitem definir o potencial de geração, o grau de maturação e o tipo de querogênio das rochas geradoras (Tissot \& Welte 1984).

A determinação da abundância da matéria orgânica presente nos sedimentos é avaliada por meio da porcentagem do carbono orgânico, incluindo outros elementos como hidrogênio, nitrogênio e enxofre (Jarvie 1991). A proporção dos elementos depende da origem, do estado de preservaçáo, da idade e da evolução térmica da matéria orgânica.

O carbono orgânico constitui o teor mínimo de matéria orgânica necessária para originar uma acumulação de óleo ou gás, viável economicamente.

Os dados quantitativos dos resultados do COT estudados na rocha fornecem informaçóes para determinar o potencial de geração dos hidrocarbonetos.

A análise dos dados de pirólise Rock-Eval possibilita avaliar a qualidade da matéria orgânica presente na seção, relacionando com os resultados do COT.

Os resultados do estudo do COT e da pirólise RockEval foram mostrados em gráficos, tabelas e diagrama de "Van Krevelen".

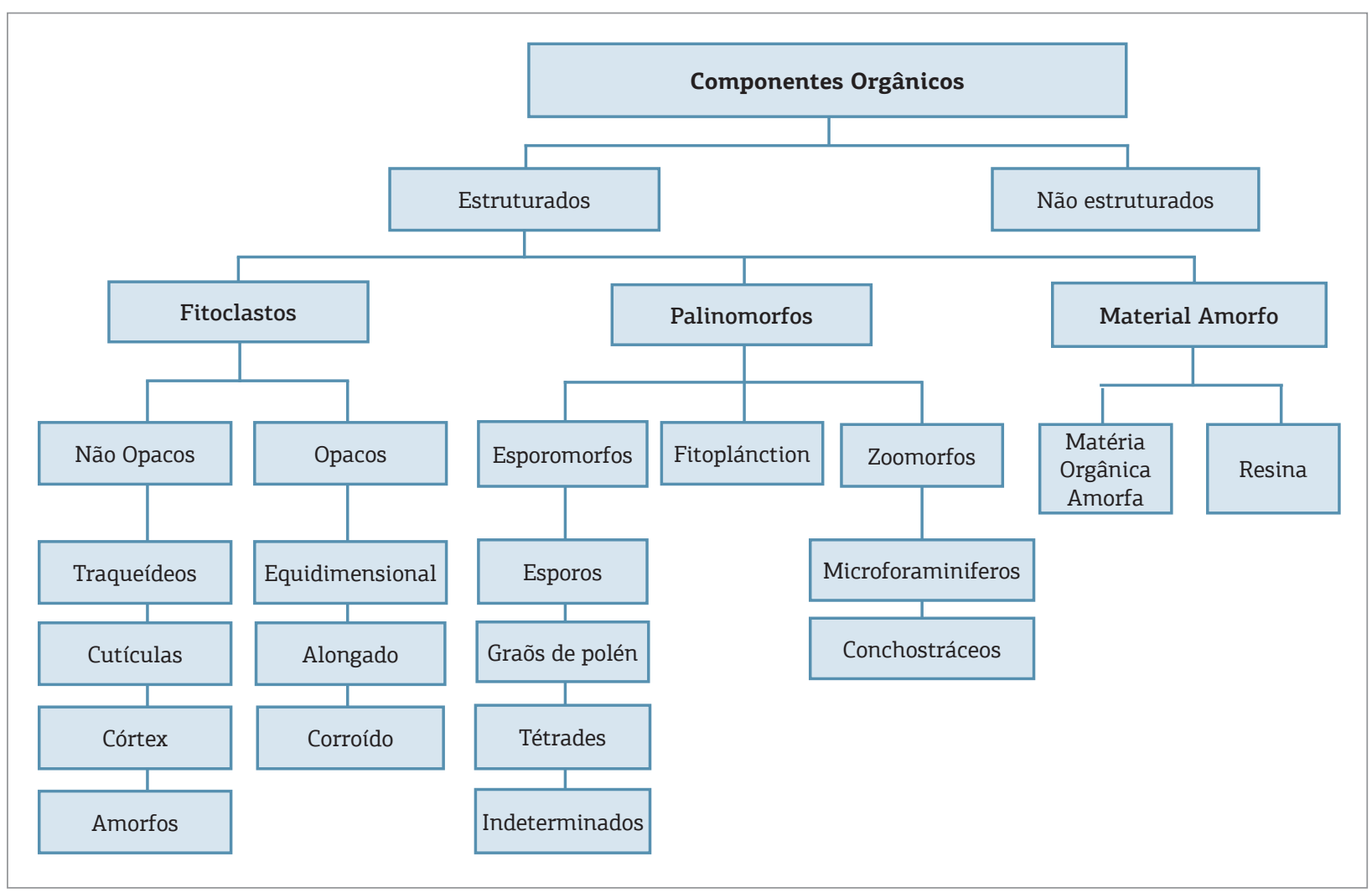

Figura 4. Classificação dos grupos de componentes orgânicos estruturados e não estruturados (Tyson 1995). 


\section{Preparação das amostras para carbono orgânico total}

Para a análise do COT, foram utilizadas 51 amostras do poço, seguindo as etapas de preparação conforme o fluxograma apresentado na Fig. 5.

As amostras foram selecionadas dos testemunhos, com intervalos de $30 \mathrm{~cm}$ ou 1,0 m, seguindo para o processo de britagem para fragmentação e pulverização em gral de porcelana a fim de obter partículas de aproximadamente 200 $\mu \mathrm{m}$. Após esta etapa, o material foi submetido a uma peneira de 80 mesh e o pó armazenado em frascos identificados pela profundidade da amostra.

A pesagem do material foi realizada no aparelho $\mathrm{LECO}^{\circ}$ SC - 444, no qual houve a queima do resíduo insolúvel (RI) e a medida das quantidades de $\mathrm{CO}_{2}$ e $\mathrm{SO}_{2}$ liberados por meio de um detector de infravermelho, que expressa, em porcentagem de peso relativo à amostra original, os teores de carbono orgânico e enxofre.

\section{Preparação das amostras para pirólise Rock-Eval}

Para a obtenção dos dados de pirólise Rock-Eval, foram selecionadas 41 amostras que apresentaram os valores de COT superiores a $1,0 \%$.

A técnica de pirólise Rock-Eval foi desenvolvida (Espitalié et al. 1977; 1985) no Instituto Francês de Petróleo e determina os parâmetros para a correlação das razóes $\mathrm{H} / \mathrm{C}$ e $\mathrm{O} / \mathrm{C}$, provenientes da análise elementar com os parâmetros IH e IO, provenientes das análises de pirólise RockEval (Espitalié et al. 1977).

As amostras selecionadas do material foram submetidas ao equipamento para o aquecimento em atmosfera inerte de 300 a $500^{\circ} \mathrm{C}$, utilizando hélio com gás carreador. Os detectores de ionização de chama e condutividade térmica mediram os hidrocarbonetos e $\mathrm{CO}_{2}$ liberados.

Os voláteis são liberados em três fases de temperaturas crescentes, as quais permitem a obtenção de parâmetros como: o pico S1, que representa os hidrocarbonetos livres na rocha gerados e que encontram-se presentes na rocha geradora; o S2, que representa os hidrocarbonetos derivados pelo craqueamento térmico primário; o $\mathrm{S} 3$, o qual relaciona o dióxido de carbono $\left(\mathrm{CO}_{2}\right)$ liberado durante a pirólise Rock-Eval, representando a quantidade de oxigênio presente no querogênio; a temperatura máxima, que corresponde àquela em que ocorre o pico S2; o índice de hidrogênio (IH), usado para determinar o tipo, a origem e o estado de preservação do querogênio; e o índice de oxigênio (IO).

Os dados do IH e IO obtidos na análise foram plotados no diagrama "Van Krevelen" para diferenciar os quatro tipos básicos de querogênio (I, II, III e IV), considerando o material termicamente pouco evoluído.

Segundo a classificaçáo de Tyson (1995), o querogênio do tipo I é caracterizado por ser rico em hidrogênio e pobre em oxigênio, correspondendo à melhor composição de matéria orgânica para a geração de hidrocarbonetos líquidos e gasosos. O tipo II é menos rico em hidrogênio do que o I, mas é considerado adequado para a formação de grandes acumulaçôes de hidrocarbonetos. Já o III é constituído por matéria orgânica com muito oxigênio e pouco hidrogênio, sendo propício para a geração de hidrocarbonetos gasosos. O querogênio do tipo IV não possui potencial para a geração de óleo ou gás, e é constituído por matéria orgânica oxidada.

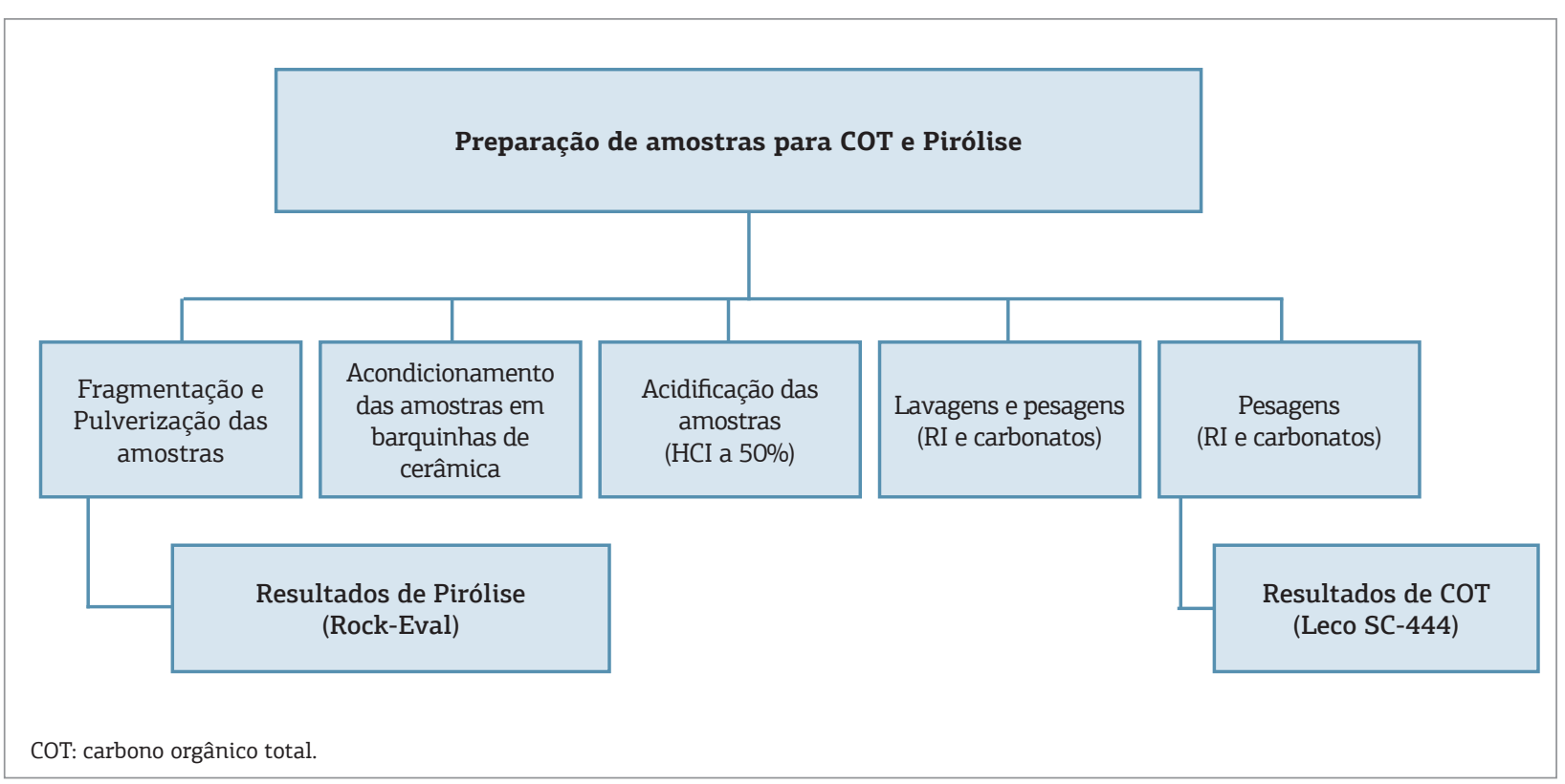

Figura 5. Fluxograma das etapas de preparação de amostras para carbono orgânico total e pirólise Rock-Eval. 


\section{RESULTADOS PALINOFACIOLÓGICOS}

As análises visuais do querogênio mostram que o material orgânico particulado é constituído, principalmente, por elementos de origem lacustre, com presença, mesmo que rara, de paleomicroplâncton marinho.

O material orgânico amorfo, seguido por fitoclastos e palinomorfos, domina em praticamente todo o intervalo da seção.

Foi possível reconhecer e identificar, por meio da microscopia de luz branca transmitida e ultravioleta incidente, três grupos de querogênio: fitoclastos, palinomorfos e material orgânico amorfo.
Os fitoclastos estão presentes em grande parte da seção e são encontrados em todas as formas e tamanhos, sendo identificados: opacos, não opacos e traqueídeos (Fig. 6).

Os opacos são caracterizados por cor preta, tamanhos variáveis, formas alongadas e equidimensionais, com contornos nítidos e retilíneos e sem fluorescência (Fig. 6A).

Já os não opacos, apresentam cor marrom alaranjada, com formas equidimensionais e apresentam ausência de fluorescência (Fig. 6B).

Os traqueídeos têm cores que variam de marrom-claro alaranjado a marrom-escuro (Fig. 6D); possuem formato equidimensional a alongado; sua estrutura interna apresenta o estômato visível e apresentam ausência de fluorescência (Fig. 6C).

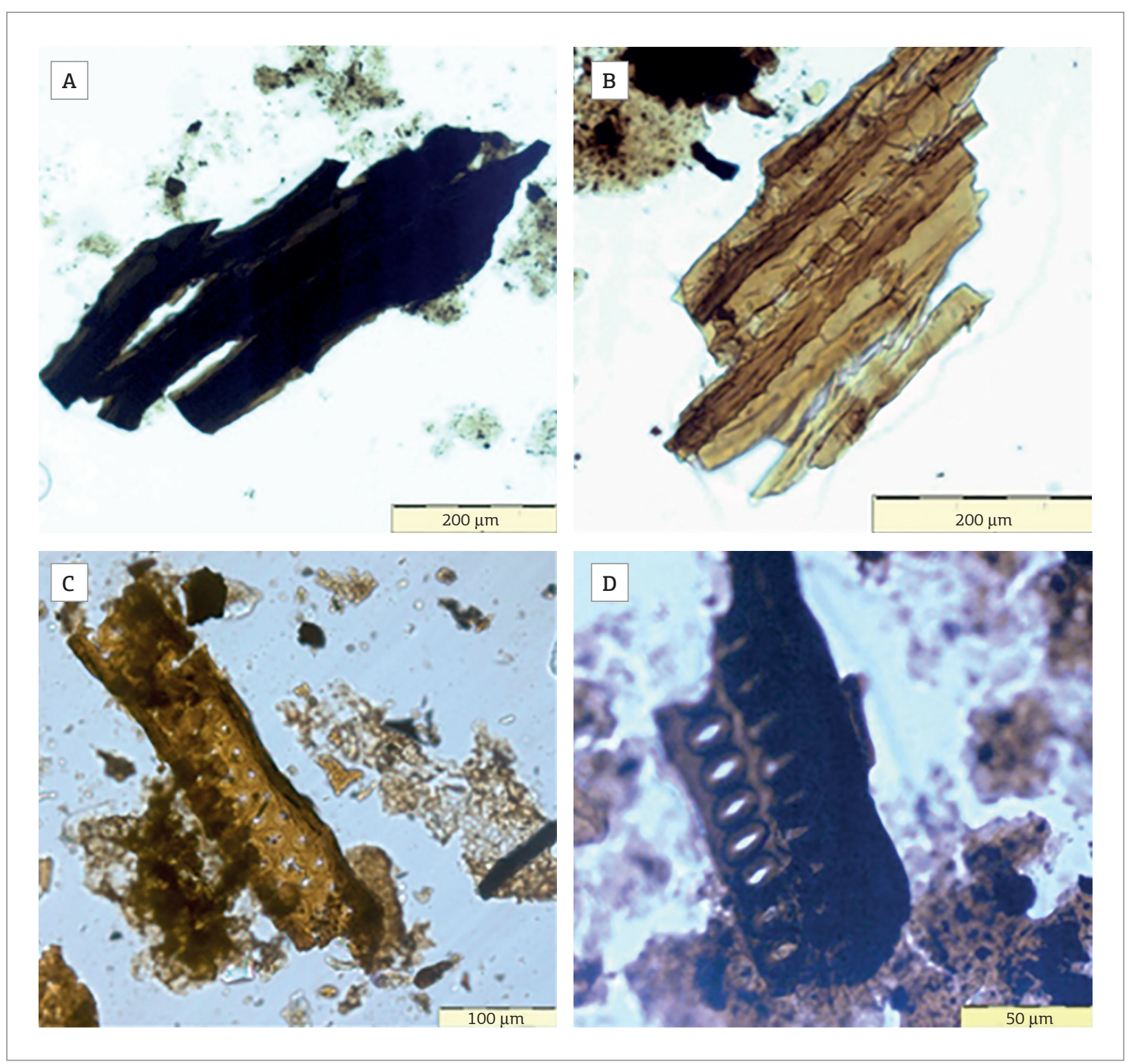

Figura 6. Fotomicrografia em luz branca transmitida. (A) Fitoclasto opaco; (B) Fitoclasto não opaco; (C) Traqueídeo com estômato visível; (D) Traqueídeo. 
Os elementos que correspondem ao grupo dos palinomorfos são representados por grãos de pólen e esporos. Os palinomorfos são caracterizados por apresentarem, quando submetidos à luz branca transmitida, coloração amarelo-claro a marrom e, à ultravioleta, fluorescência baixa.

Os grãos de pólen são indicados predominantemente pela espécie Classopollis classoides Pflug (Pflug 1953).

Observam-se, pontualmente, palinomorfos dispostos em tétrades e aglomerados (Fig. 7A), ocorrência dos grãos de pólen bissacados e esporos triletes (Fig. 7B).

A matéria orgânica amorfa (Fig. 8) apresenta-se predominantemente dispersa, com coloração marrom-claro, e globosa, com coloração marrom-escuro.

\section{Análise quantitativa do querogênio}

O resultado quantitativo dos componentes orgânicos apresentou valores percentuais distribuídos ao longo das profundidades amostradas do poço, conforme ilustrado na Fig. 9.

A matéria orgânica amorfa mostrou predominância na maior parte das amostras analisadas, variando de 40 a 90\%, com média de $67 \%$.

A quantificação dos palinomorfos obteve valores entre 1 a $40 \%$, tendo uma média de $12 \%$ na distribuição total do querogênio.

Os fitoclastos dos subgrupos dos opacos, não opacos e traqueídeos apresentaram registro com valores médios de 45\%.

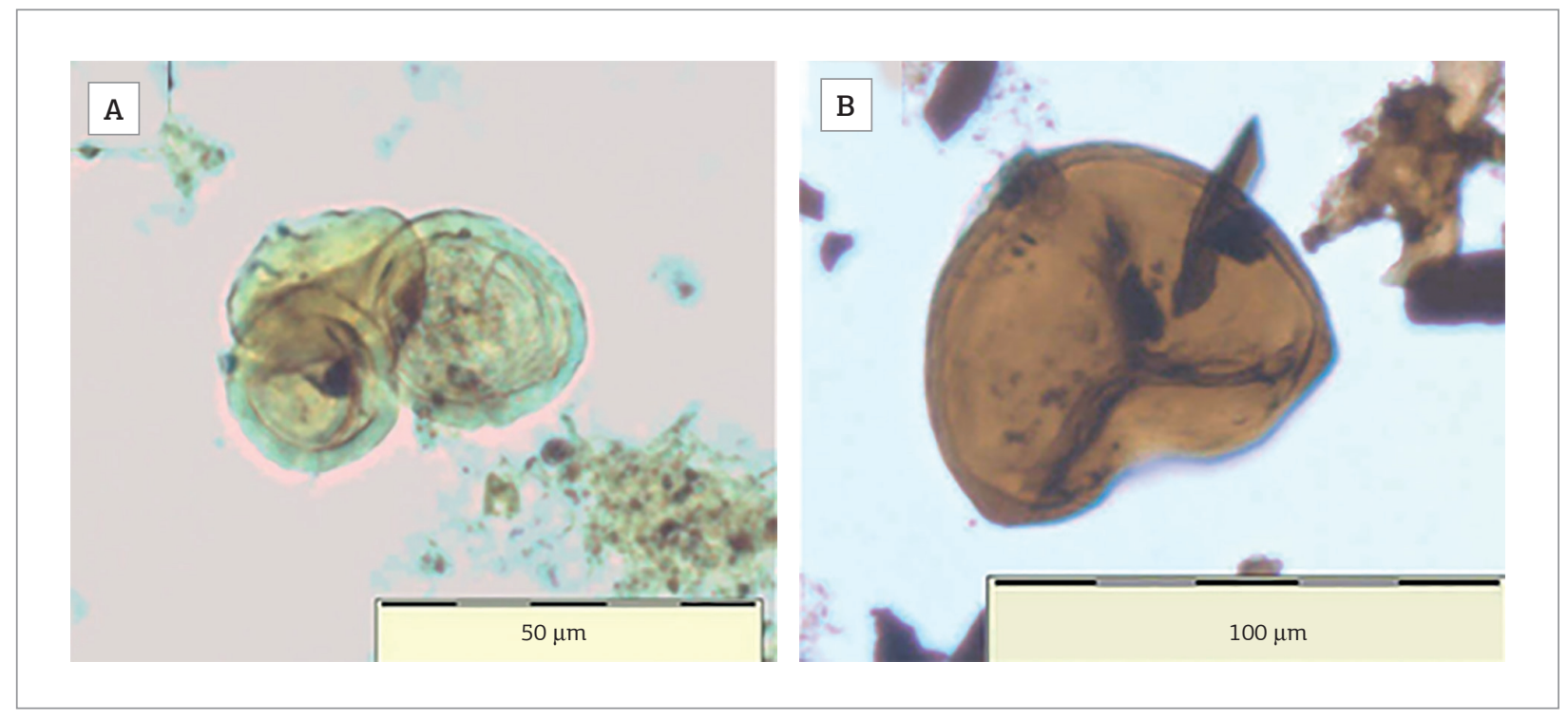

Figura 7. Fotomicrografia das espécies de palinomorfos. (A) Tétrade dos grãos de pólen da espécie Classopollis classoides; (B) Esporo da espécie Deltoidospora hallii.

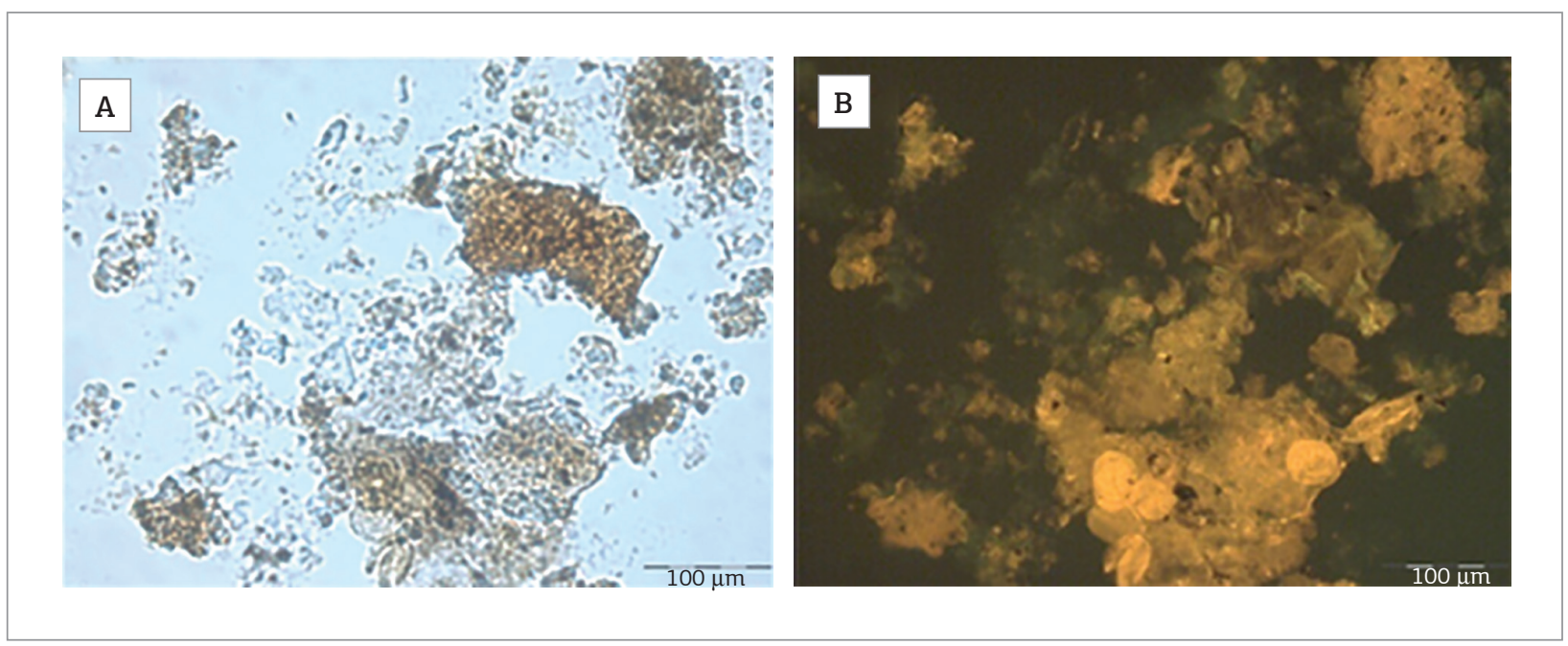

Figura 8. Fotomicrografia da matéria orgânica amorfa. (A) Luz branca transmitida amostra 9-PEC-41-SE 294,5 m; (B) Luz ultravioleta amostra 9-PEC-41-SE 208,0 m. 


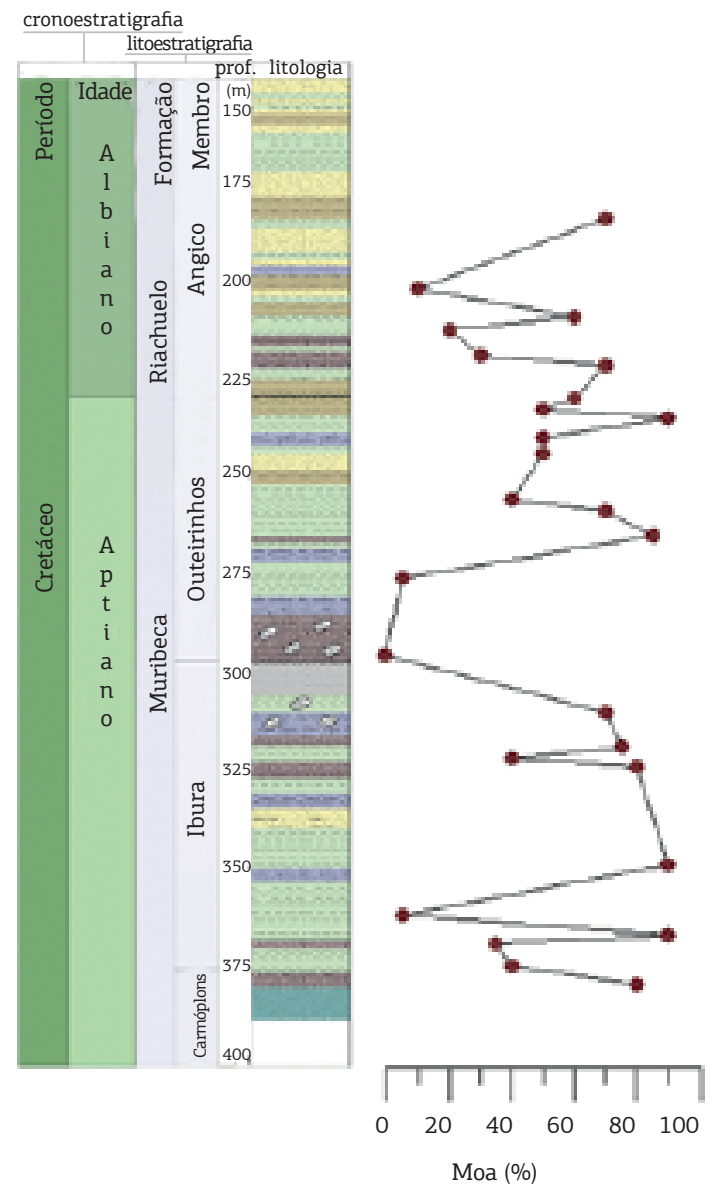

Bacia de Sergipe Poço 9-PEC-41-SE
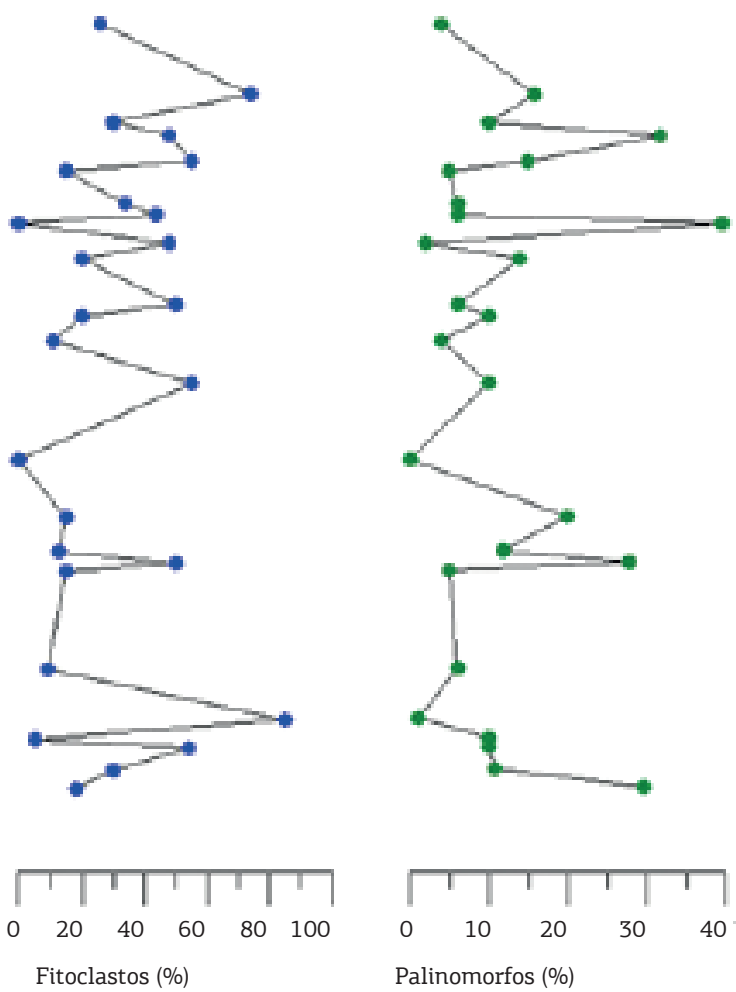

Palinomorfos (\%)

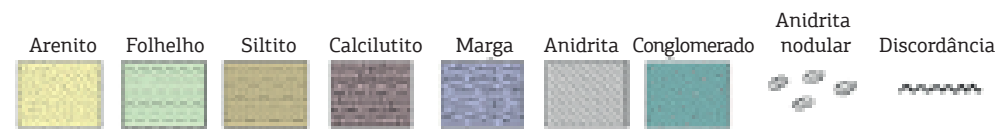

MOA: matéria orgânica amorfa.

Figura 9. Gráfico representando a porcentagem relativa entre os grupos de querogênio (matéria orgânica amorfa, fitoclastos e palinomorfos).

Os constituintes do querogênio do subgrupo dos fitoclastos opacos são abundantes na maioria das amostras da seção em relaçáo ao não opacos.

A maior proporção na composiçáo total do querogênio na seçáo analisada é representada pela matéria orgânica amorfa (Fig. 10).

\section{Análise da qualidade de preservação do material orgânico}

$\mathrm{O}$ estado de preservação do material foi examinado utilizando-se os critérios ópticos, por meio de avaliação da intensidade de fluorescência.

O resultado obtido permitiu identificar a ocorrência de matéria orgânica amorfa com fluorescência alta (Fig. 11A) e moderada à baixa (Fig. 11B) e com ausência de fluorescência (Fig. 11C).

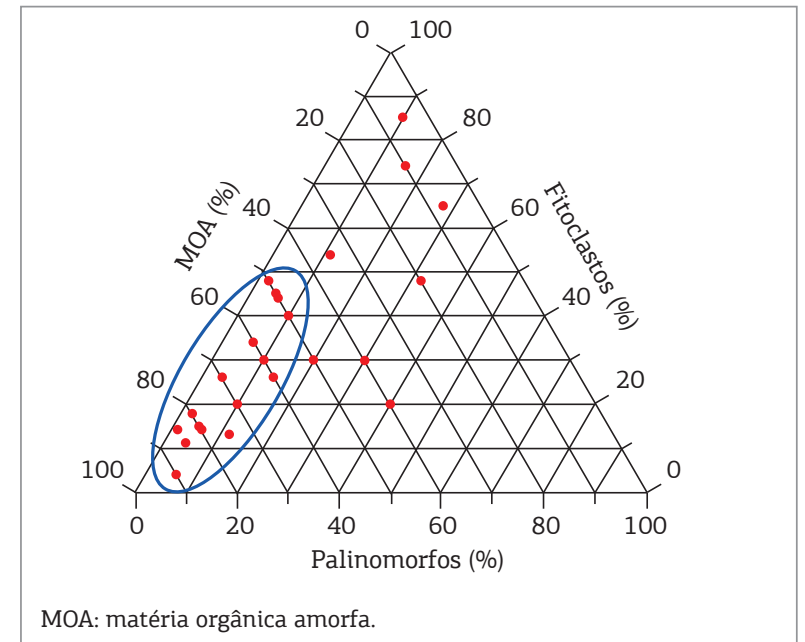

Figura 10. Gráfico ternário utilizado para identificar o predomínio dos constituintes orgânicos da seção estudada. 
Os fitoclastos e palinomorfos, em geral, apresentam grau de fluorescência baixo.

A matéria orgânica amorfa ocorre na seção predominantemente na forma globosa, com moderado a alto grau de fluorescência. Sua identificação constitui um bom indicativo para determinar o grau de maturação e preservação da matéria orgânica.

As características da fluorescência da matéria orgânica amorfa, obtidas na análise de cor e intensidade, determinam seu bom estado de preservação.
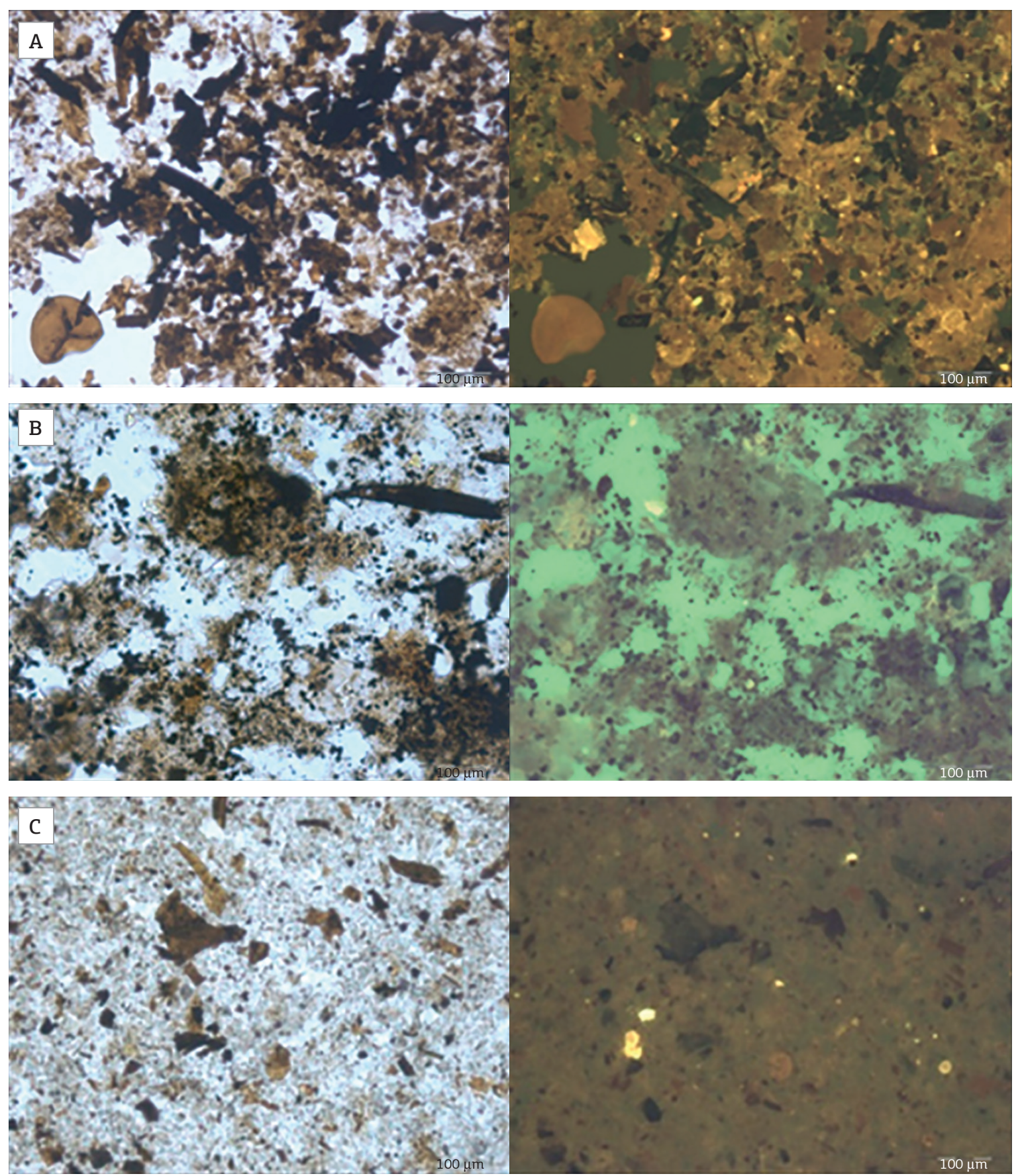

Figura 11. Fotomicrografia da matéria orgânica amorfa em luz branca transmitida (esquerda) e ultravioleta fluorescente à direita. (A) Amostra 211,5 m com fluorescência alta; (B) Amostra 264,0 m com fluorescência moderada à baixa; (C) Amostra 201,0 m com ausência de fluorescência. 


\section{Caracterização das palinofácies}

Com a integração dos resultados das análises qualitativas de preservação do material orgânico e quantitativas do querogênio presente na seção, foi possível caracterizar e identificar três palinofácies distintas para a seção.

\section{Palinofácies I}

Ocorre em dois intervalos da seção, na porção intermediária e no topo. Caracteriza-se por apresentar maior contribuição de matéria orgânica amorfa comparada com os demais constituintes, representando em torno de 50 a 90\%.
A matéria orgânica amorfa possui alto grau de fluorescência e preservação, apresentando-se no material, na forma dispersa e globosa (Fig. 12B).

Tais características apontam para uma deposição em ambiente redutor, adequado para a preservação da matéria orgânica amorfa.

\section{Palinofácies II}

Caracteriza-se por apresentar maior domínio de matéria orgânica amorfa globosa oxidada, com regular à baixa intensidade de fluorescência e preservação (Fig. 13B).

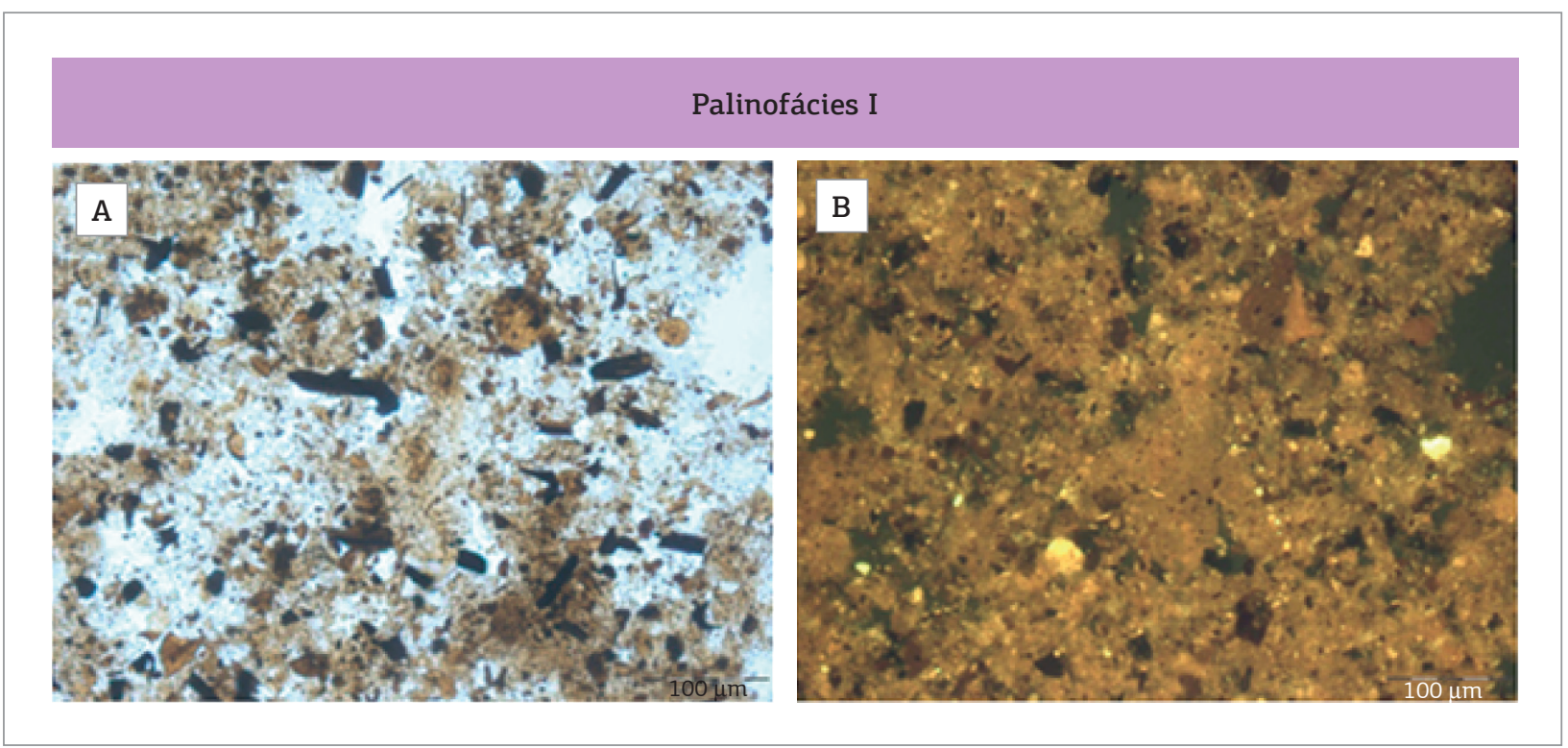

Figura 12. Caracterização da palinofácies I. (A) Luz branca transmitida; (B) Fluorescência.

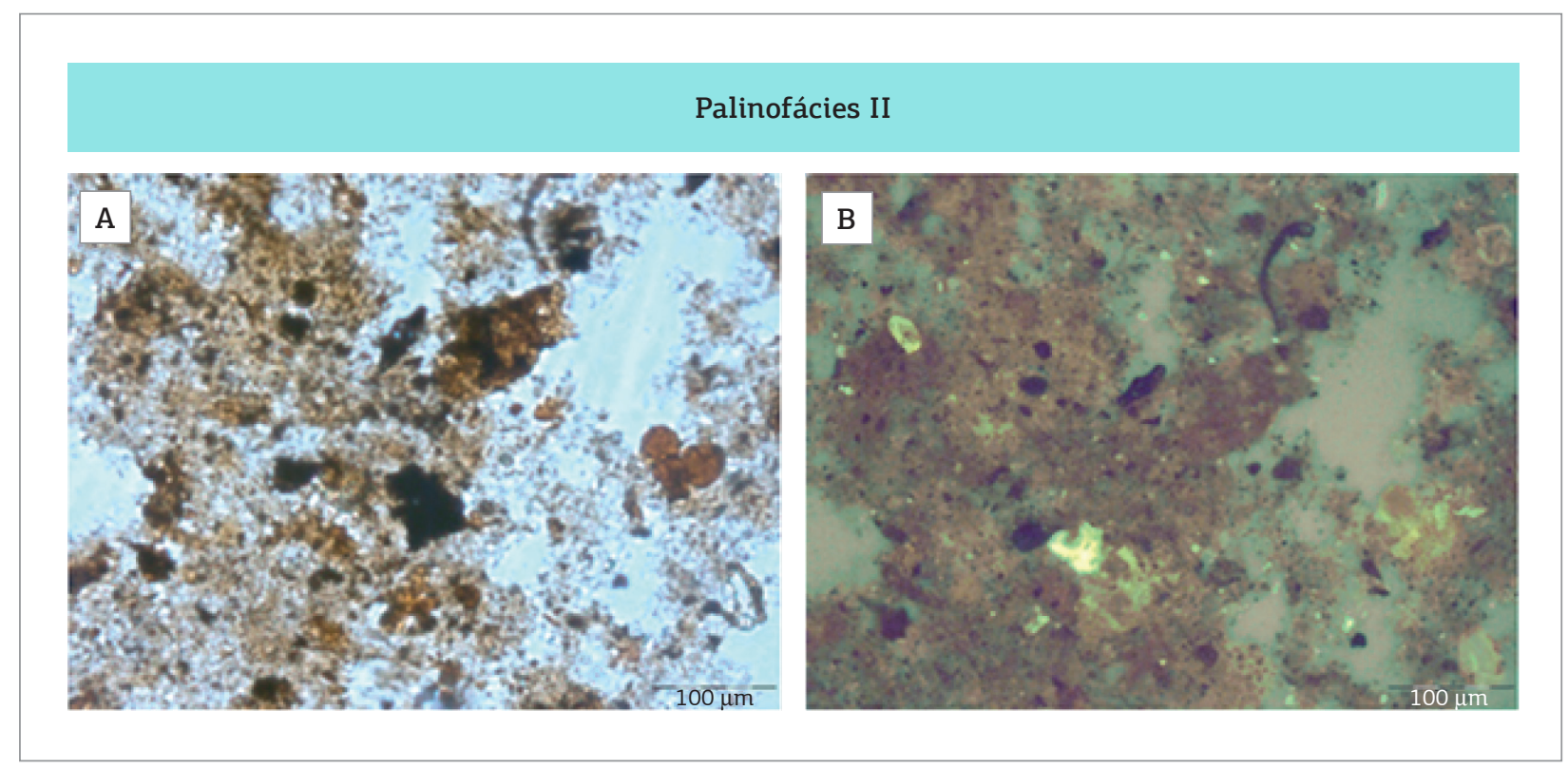

Figura 13. Caracterização da palinofácies II. (A) Luz branca transmitida; (B) Luz ultravioleta com fluorescência regular à baixa. 
Possui baixa representatividade de fitoclastos e palinomorfos, resultante provavelmente de uma maior exposição a açōes oxidantes.

\section{Palinofácies III}

Apresenta baixa preservação e ausência de fluorescência da matéria orgânica amorfa (Fig. 14B).

Em termos percentuais, esta palinofácies é constituída por $50 \%$ de contribuição da matéria orgânica amorfa, $40 \%$ de fitoclastos e raríssimos palinomorfos.
As três palinofácies definidas (Fig. 15) apresentam intervalos que marcam as mudanças de ambiente deposicional do material estudado.

A palinofácies I é caracterizada pelo intervalo de maior preservação da matéria orgânica amorfa com altos valores de fluorescência, típicos de ambiente redutor. Apresenta elementos do paleomicroplâncton marinho no intervalo correspondente à passagem do Aptiano-Albiano (Membros Oiteirinhos e Angico), correspondendo as primeiras ingressóes marinhas.

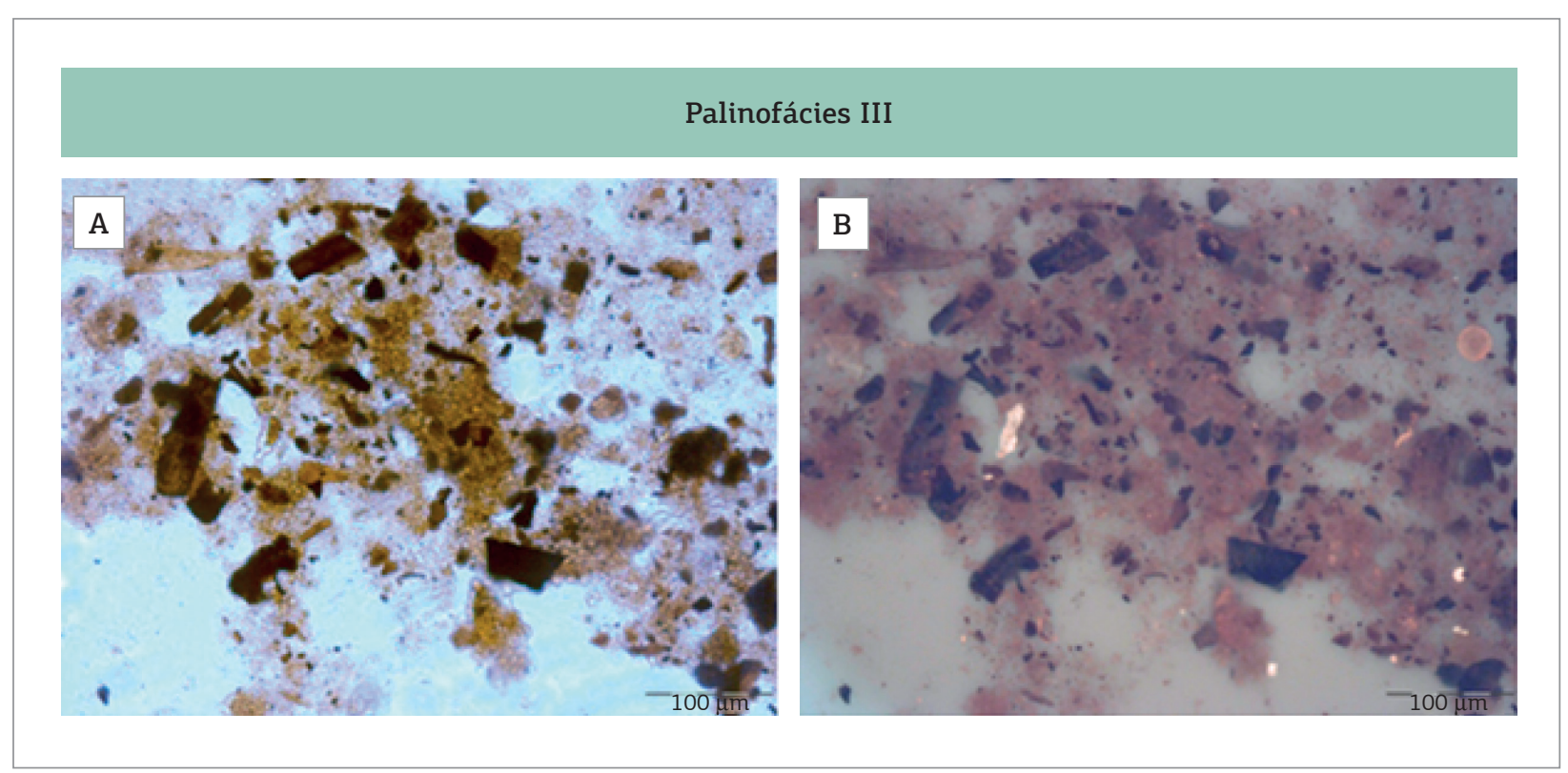

Figura 14. Caracterização da palinofácies III. (A) Luz branca transmitida; (B) Luz ultravioleta com ausência de fluorescência.

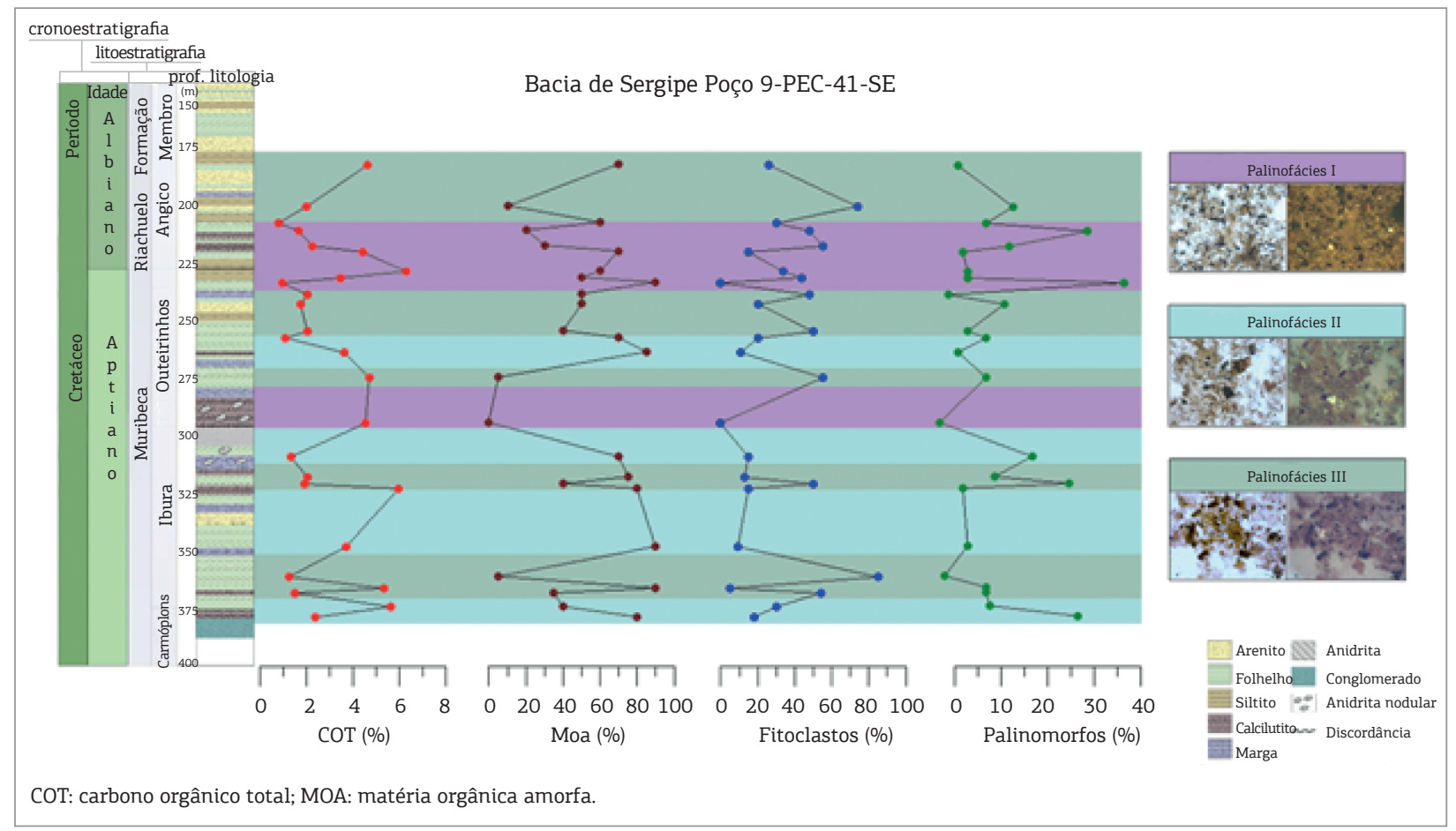

Figura 15. Gráficos com a relação entre os grupos de querogênio, palinofácies e carbono orgânico total. 
A distribuição das palinofácies II e III ocorre predominantemente, de forma cíclica, nas rochas que correspondem ao Membro Ibura e Oiterinhos, abrangendo a Formaçáo Muribeca, depositadas em ambientes lacustres a plataformais. O conteúdo orgânico apresenta características típicas de material submetido a uma possível exposição oxidante.

\section{Análises palinológicas}

Ao longo de toda a seção, observa-se baixa representatividade de palinomorfos, em que a espécie Classopollis classoides tem um destaque em relação às demais.

Os palinomorfos foram identificados (Figs. 16 e 17), seguindo a classificação proposta por Potonié (1958), por conseguirem agrupar satisfatoriamente os morfogêneros conforme suas características morfológicas mais evidentes e, principalmente, vegetais que produzam grãos similares.

Os palinomorfos foram devidamente identificados e registrados por meio da coordenada England Finder, e fotomicrografados com aumento de $100 \mathrm{x}$.

\section{RESULTADOS DA GEOQUÍMICA ORGÂNICA}

\section{Análise do carbono orgânico total e enxofre}

Os resultados obtidos pela análise do COT (Fig. 18) apresentaram valor máximo de $6,39 \%$, permitindo
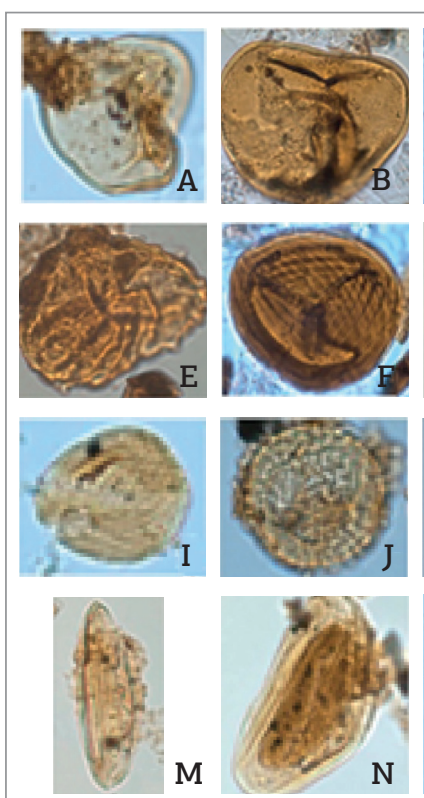
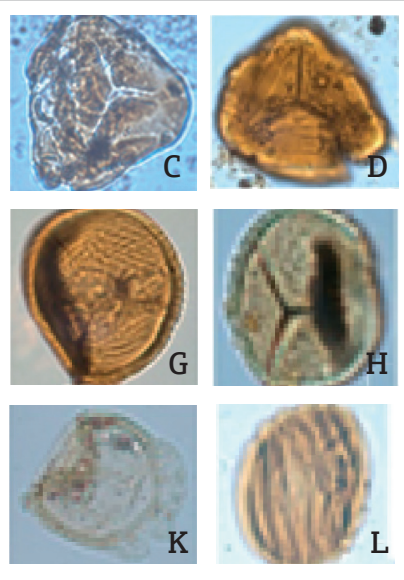

K
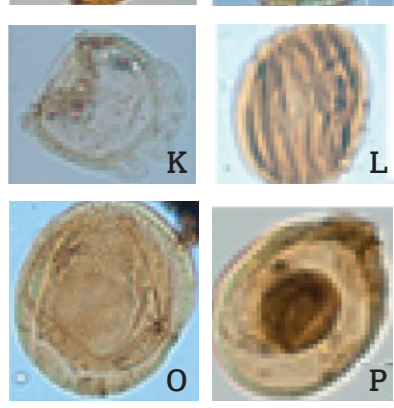

\begin{tabular}{|l|c|c|c|}
\hline \multicolumn{3}{|c|}{ Registro das espécies ilustradas no poço 9-PEC-41-SE } \\
\hline Espécies & Fig. & $\begin{array}{c}\text { Prof. } \\
\text { (m) }\end{array}$ & $\begin{array}{c}\text { England } \\
\text { Finder }\end{array}$ \\
\hline Cyathidites australis Couper, 1953 & $1 / \mathrm{A}$ & 275,0 & D 39-3 \\
\hline Deltoidospora hallii Miner, 1935 & $1 / \mathrm{B}$ & 201,0 & L 31 \\
\hline Deltoidospora sp. & $1 / \mathrm{C}$ & 234,0 & $\mathrm{~N} 2$ \\
\hline Cicatricosisporites sp. & $1 / \mathrm{D}$ & 309,0 & $\mathrm{~S} \mathrm{40-4}$ \\
\hline Cicatricosisporites sp. & $1 / \mathrm{E}$ & 378,5 & O 33-3 \\
\hline Cicatricosisporites sp. & $1 / \mathrm{F}$ & 201,0 & E 39-2 \\
\hline Cicatricosisporites avnimelechi Horowitz, 1970 & $1 / \mathrm{G}$ & 329,0 & - \\
\hline Cicatricosisporites avnimelechi Horowitz, 1970 & $1 / \mathrm{H}$ & 366,0 & E 27 \\
\hline Cicatricosisporites avnimelechi Horowitz, 1970 & $1 / \mathrm{I}$ & 243,0 & K 34-4 \\
\hline Hamulatisporis albertensis Srivastava, 1972 & $1 / \mathrm{J}$ & 275,0 & K 39 \\
\hline Vitreisporites sp1 Dino, 1992 & $1 / \mathrm{K}$ & 211,5 & T 33-3 \\
\hline Gnetaceapollenites uesuguii Lima, 1980 & $1 / \mathrm{L}$ & 201 & Q 29 \\
\hline Equisetosporites montanaensis Brenner, 1968 & $1 / \mathrm{M}$ & 329,0 & H 47 \\
\hline Equisetosporites maculosus Dino, 1994 & $1 / \mathrm{N}$ & 275,0 & R 35-3 \\
\hline Classopollis classoides Pflug, 1953 & $1 / 0$ & 275,0 & T 31 \\
\hline Circulina meyeliana Klaus, 1960 & $1 / \mathrm{P}$ & 275,0 & R 42-4 \\
\hline
\end{tabular}

Figura 16. Fotomicrografia ilustrativa dos palinomorfos presentes no material estudado.
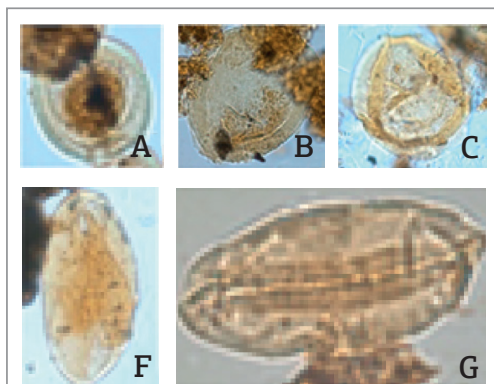

$\mathrm{F}$
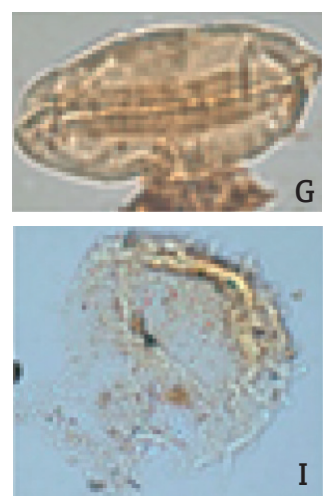
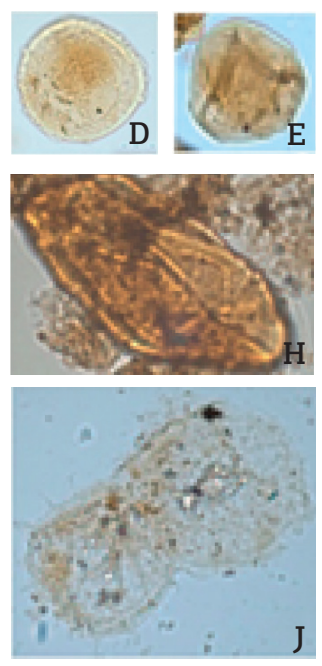

Registro das espécies ilustradas no poço 9-PEC-41-SE

\begin{tabular}{|l|c|c|c|}
\hline Espécies & Fig. & $\begin{array}{c}\text { Prof. } \\
(\mathbf{m})\end{array}$ & $\begin{array}{c}\text { England } \\
\text { Finder }\end{array}$ \\
\hline Circulina meyeliana Klaus, 1960 & $1 / \mathrm{A}$ & 275,0 & K $42-2$ \\
\hline Araucariacites australis Cookson, 1947 & $1 / \mathrm{B}$ & 366,0 & $\mathrm{R} 29-2$ \\
\hline Araucariacites australis Cookson, 1947 & $1 / \mathrm{C}$ & 201,0 & T 37-1 \\
\hline Inaperturopollenites turbatus Habib, 1969 & $1 / \mathrm{D}$ & 275,0 & X 34-3 \\
\hline Inaperturopollenites sp. & $1 / \mathrm{E}$ & 275,0 & F 35 \\
\hline Cycadopites sp. & $1 / \mathrm{F}$ & 361,0 & $\mathrm{U} 37-1$ \\
\hline Cycadopites sp. & $1 / \mathrm{G}$ & 378,5 & X 47 \\
\hline Bennettitaepollenites sp. & $1 / \mathrm{H}$ & 378,5 & $\mathrm{R} 44$ \\
\hline Dinoflagelado N.I. & $1 / \mathrm{I}$ & 211,5 & G 40 \\
\hline Dinoflagelado N.I. & $1 / \mathrm{J}$ & 211,5 & EF V 35-3 \\
\hline
\end{tabular}

Figura 17. Fotomicrografia ilustrativa dos palinomorfos presentes no material estudado. 


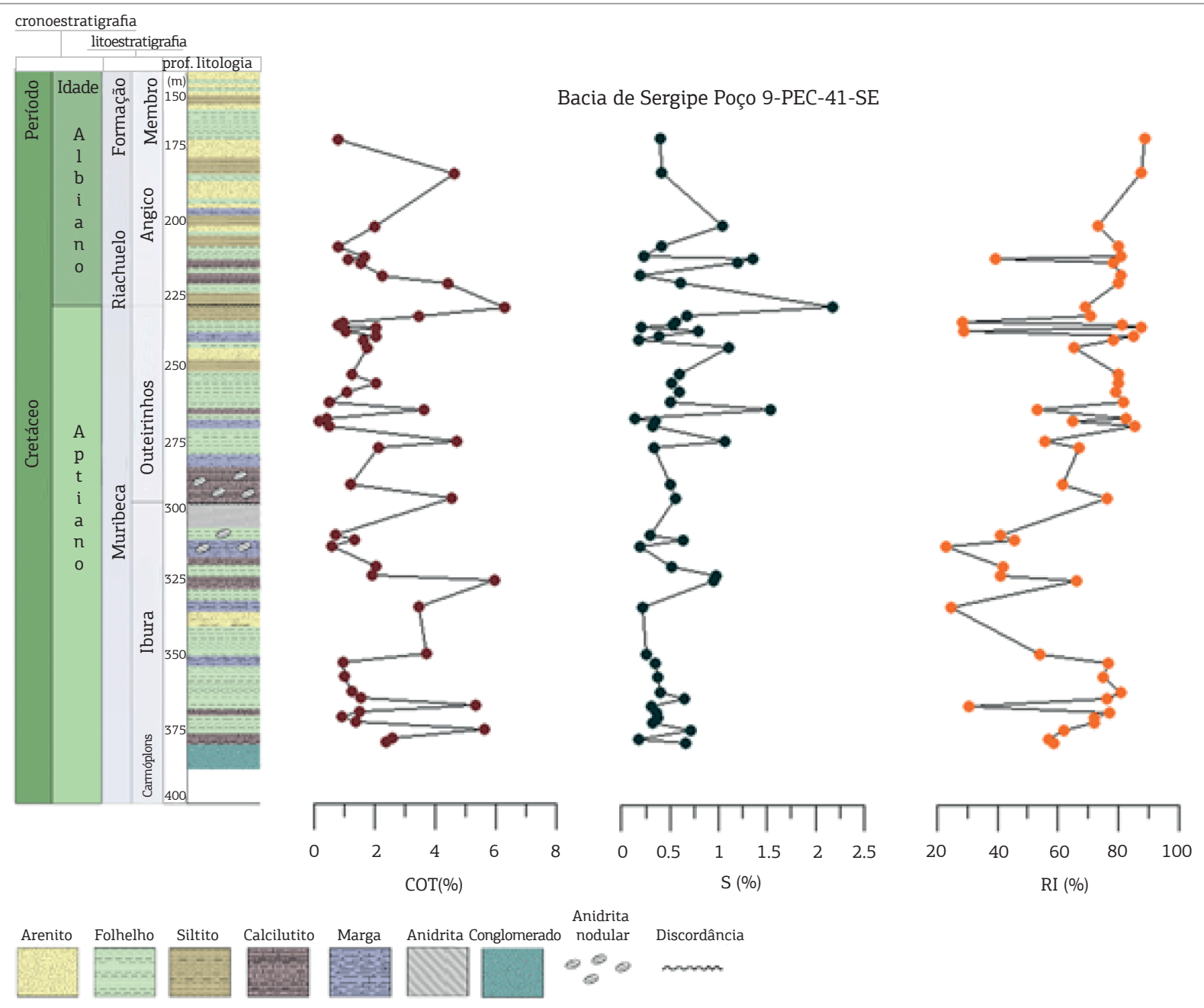

COT: carbono orgânico total; S: enxofre; RI: resíduo insolúvel.

Figura 18. Gráfico da distribuição do carbono orgânico total, enxofre e resíduo insolúvel em porcentagem.

caracterizar um bom potencial de geração dos hidrocarbonetos para a seção.

Os teores de COT ao longo de toda seção variaram de 0,76 a $6,29 \%$, estando a maioria das amostras no intervalo entre 2,0 a $6,0 \%$.

Os dados do RI apresentam predominantemente valores acima de 60\%, representando folhelhos, e de 20 a 40\%, os carbonatos.

Os valores do $S$ mais baixos entre 0 a $0,5 \%$ correspondem aos de COT mais altos, entre 4 e $6 \%$.

\section{Análise da pirólise Rock-Eval}

Os resultados obtidos na análise da pirólise RockEval foram utilizados para classificar o tipo e a origem do material orgânico presente. Os dados foram plotados no diagrama de "Van Krevelen", que permite relacionar o IH e o IO para classificação do querogênio em I, II, III ou IV.
O grau de preservação da matéria orgânica pode ser representado na relação entre o índice de hidrogênio e o teor de COT, sendo possível avaliar a qualidade da matéria orgânica, a preservação e o seu potencial gerador.

Por meio das análises obtidas nas amostras do poço 9-PEC41-SE, foi possível classificar o querogênio do tipo II (Fig. 19), composto por folhelhos ricos em matéria orgânica amorfa, que, apesar de possuírem um teor menor de hidrogênio em relação ao I, ainda são ricos em hidrogênio e pobres em oxigênio.

As informaçôes do IH apresentaram resultados entre 200 e $550 \mathrm{mg} \mathrm{HC} / \mathrm{g}$ de COT, caracterizando um bom potencial para a geração de óleo e gás.

A Fig. 20 demonstra os gráficos gerados, relacionando os dados de pirólise Rock-Eval com as palinofácies definidas pelos parâmetros da petrografia. As análises das palinofácies I e II apontam os mais elevados valores de IH e uma diminuição do $\mathrm{IO}$, o que indica uma maior preservação da matéria orgânica, ligada diretamente ao aumento dos teores de COT. 
A palinofácies III apresenta valores de IH inferiores em relação aos de IO, portanto a matéria orgânica esteve possivelmente exposta a oxidações, relacionada com os menores valores de COT.

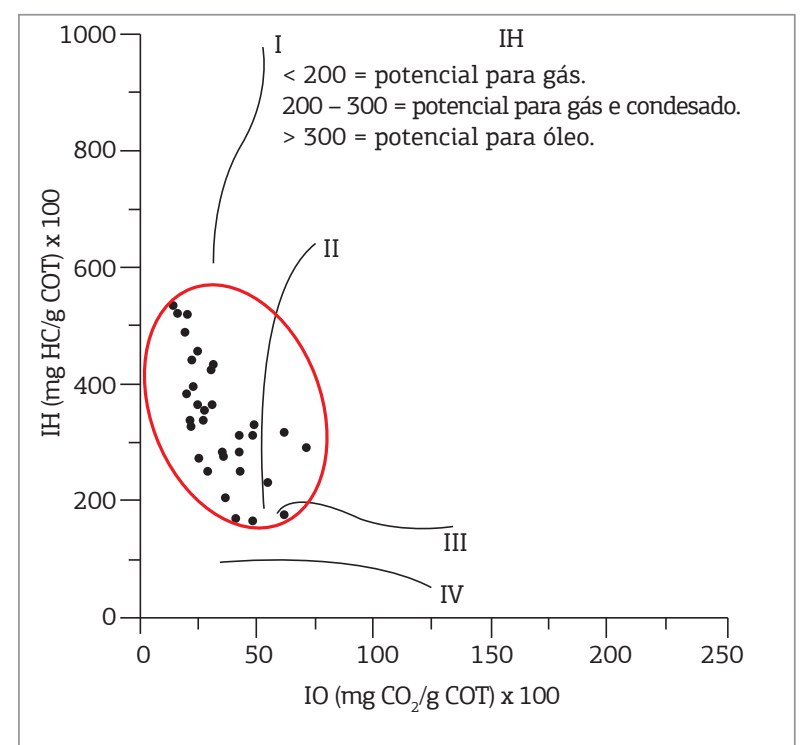

Figura 19. Diagrama de Van Krevelen com a distribuição das amostras analisadas, destacando o predomínio do querogênio do tipo II.

\section{RESULTADOS DO POTENCIAL DE GERAÇÃO}

A análise da evolução térmica da matéria orgânica integrou a interpretação dos valores de ICE e os resultados de temperatura máxima, obtidos pela pirólise Rock-Eval.

Foram aplicados como parâmetros da técnica de obtenção do ICE os grãos de pólen do gênero Classopollis, devido a sua alta representatividade ao longo de toda a seção.

Baseados na tabela padrão da Robertson Research, tais resultados apresentam valores de 4,0 a 4,5 de ICE, mostrando que a seção encontra-se predominantemente na fase imatura de geração.

O estado de evoluçáo térmica do querogênio apresenta-se no grau de maturação imaturo, que corresponde à refletância da vitrinita entre 0,3 e $0,4 \% \mathrm{R}_{\mathrm{o}}$.

Os resultados obtidos para a temperatura máxima estão entre 390 a $432^{\circ} \mathrm{C}$, que correspondem ao intervalo entre a fase imatura e a matura para a geração de hidrocarbonetos. Tais resultados vêm corroborar com aqueles da análise do ICE, que apresentou valores entre 4,0 a 4,5 .

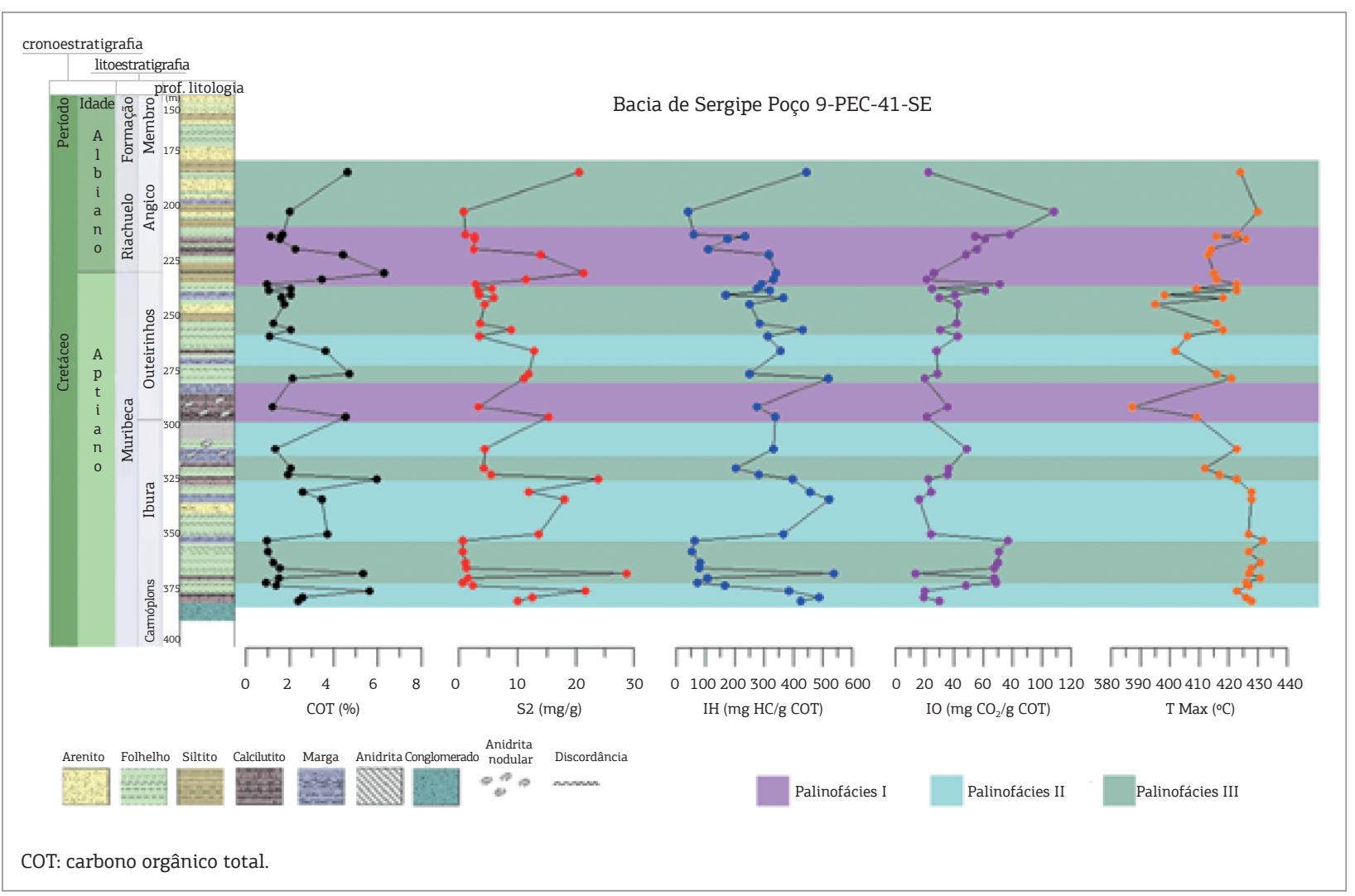

Figura 20. Distribuição das palinofácies com carbono orgânico total, pico S2, índices de hidrogênio e oxigênio e temperatura máxima. 


\section{DISCUSSÕES E CONCLUSÕES}

Os resultados das análises palinofaciológicas e da geoquímica orgânica, obtidos das análises de 51 amostras do poço 9-PEC-41-SE, da Bacia de Sergipe, mostram que a matéria orgânica amorfa é o grupo do querogênio dominante e encontra-se em bom estado de preservação em praticamente toda a seção, com alto grau de fluorescência. Subordinadamente, observa-se a presença de componentes alóctones, tais como: fitoclastos opacos e não opacos e grãos de pólen e esporos. O domínio dos grãos de pólen, representado pela espécie Classopollis classoides, sugere um paleoclima árido a semiárido na época de deposição. Ressalta-se a presença dos cistos de dinoflagelados no topo da seção, indicativo das primeiras ingressóes marinhas ocorridas no final do Aptiano.

A partir dos resultados qualitativos e quantitativos da matéria orgânica, foi possível definir três palinofácies distintas para o intervalo estudado.

A palinofácies I é caracterizada por apresentar maior preservação da matéria orgânica amorfa, com alta intensidade de fluorescência e maiores valores de COT, os quais atingem 6,39\%. Já a II apresenta maior domínio de matéria orgânica amorfa globosa oxidada e baixa representatividade de fitoclastos e palinomorfos, e os valores de COT estão entre 1 a 4\%. A palinofácies III é distinta por apresentar domínio de matéria orgânica amorfa oxidada e seus valores de COT serem baixos de até $2 \%$.

A avaliação do potencial petrolífero da seção analisada, utilizando as ferramentas de análises palinofaciológicas e geoquímica orgânica, resultou em dados que apontam para rochas potencialmente geradoras de petróleo, com teores de COT predominantemente acima de $2 \%$, incluindo intervalos com valores de até 6,39\%.

Os dados de pirólise Rock-Eval mostram IH entre 200 e $550 \mathrm{mg} \mathrm{HC} / \mathrm{g}$ de COT, correspondendo a um bom potencial de geração de óleo e gás.

Os dados de temperatura máxima atingiram valores de $432^{\circ} \mathrm{C}$, o que confirma os resultados obtidos pela análise do ICE com valores entre 4,0 a 4,5, indicando um intervalo predominantemente imaturo.

\section{AGRADECIMENTOS}

À Petrobras, Unidade de Operaçóes de Exploração e Produção de Sergipe e Alagoas (UO-SEAL), pela liberação das amostras utilizadas no trabalho.

\section{REFERÊNCIAS}

Aquino G.S. \& Lana M.C. 1990. Exploração na Bacia de SergipeAlagoas: o "estado da arte". Boletim de Geociências da Petrobras, Rio de Janeiro, 4(1):75-84.

Barnard P.C., Collins A.G., Cooper B.S. 1981. Generation of hydrocarbons - time, temperature and source rock quality. In: Brooks J. (ed.) Organic Maturation Studies and fossil fuel exploration. London, Academic Press, p. 337-342.

Brenner G.J. 1968. Middle Cretaceous spores and pollen from northeastern Peru. Pollen et spores, 10(2):341-384.

Cainelli C. \& Mohriak W.U. 1998. Geology of Atlantic Eastern Brazilian basins. 1998. In: AAPG, International Conference $\odot$ Exhibition Short Course - Brazilian Geology Part II, Rio de Janeiro, Brazil, $67 \mathrm{p}$.

Combaz A. 1964. Les Palynofacies: Revue de Micropaleontologie. v. 7, p. 205-219.

Combaz A. 1980. Les kerogenes vus au microscope. In: Durand B. (ed.) Kerogen: insoluble organic matter from sedimentary rocks. Paris, Éditions Technip, p. 55-111.

Cookson I.C. 1947. Plant microfossils from the lignites of Kerguelen Archipelago. Antarctic Research Expedition 1929-1931 Reports, Series A2, p. 127-142.

Couper R.A. 1953. Upper Mesozoic and Cainozoic spores and pollen grains from New Zealand. New Zealand and Geology Survey Paleontology Buli, 22:1-77.
Dettmann M.E. 1963. Upper Mesozoic microfloras from southeastern Australia. Proceedings of the Royal Society of Victoria, Melbourne, 77(1):1-148.

Dino R. 1992. Palinologia, Bioestratigrafia e Paleoecologia da Formação Alagamar - Cretáceo da Bacia Potiguar, Nordeste do Brasil. Tese de Doutorado, Programa de Pós-graduação em Geologia Sedimentar, Instituto de Geociências, Universidade de São Paulo, São Paulo, 357 p.

Dino R. 1994. Some new pollen grain species from the Lower Cretaceous of northeastern Brazil. Boletim de Geociências da Petrobras, 8(2-4):257-273.

Espitalié J., Laporte J.L., Madec M., Marquis F., Leplat P., Paulet J., Boutefeu A. 1977. Methode rapide de caracterisation des roches mères, de leur potential petrolier et de leur degré d'evolution. Revue de l'Institut Français du Petrole, 32:32-42.

Espitalié J., Deroo G., Marquis F. 1985. La pyrolyse Rock-Eval et ses applications -première/deuxième partie. Revue de l'Institut Français du Petrole, Paris, 40(56):563-579.

Habib D. 1969. Middle Cretaceous palynomorph assemblages from clays near the Horizon Beta deep-sea outcrop. Micropaleontology, 16:345-379.

Horowitz A. 1970. Jurassic microflora from the northern Negev, Israel. Israel Journal of Earth Sciences, 19:153-182.

Hunt J.M. 1995. Petroleum Geochemistry and Geology. 2nd ed. New York, W.H. Freeman and Company, 743 p. 
Jarvie D.M. 1991. Total Organic Carbon (TOC) analysis. In: Merril R.K. (ed.) Source and migration processes and evaluation techniques. Treatise of Petroleum Geology, American Association of Petroleum Geologists, Tulsa, p. 113-118.

Klaus W. 1960. Sporen der Karnischen Stufe der ostalpinen Trias. Jahrbuch der Geologischen Bundesanstalt, 5:107-184.

Lima M.R. 1980. Palinologia da Formação Santana (Cretáceo do Nordeste do Brasil). III - Descrição sistemática dos polens da turma Plicates (subturma Costates). Ameghiniana, Buenos Aries, 17(1):15-47.

Mendonça Filho J.G. 1999. Aplicação de estudos de palinofácies e fácies Orgânica em rochas do Paleozoico da Bacia do Paraná, Sul do Brasil. Tese de Doutorado, Universidade Federal do Rio Grande do Sul, Santa Catarina, 2 v., 338 p.

Mendonça Filho J.G., Elias V.O., Macedo A.C.O., Iemma M.B., Menezes T.R. 2001. Estudos dos Componentes Orgânicos Particulados Presentes nos Sedimentos de Fundo da Baía de Guanabara: uma Contribuição à Caracterização da Degradação Ambiental. In: VIII Congresso Brasileiro de Geoquímica, Curitiba, Paraná, de 21 a 26 de novembro de 2001.

Mendonça Filho J.G., Menezes T.R., Mendonça J.O., Oliveira A.D., Carvalho M.A., Sant'Anna A.J. 2009. Palinofácies. In: Carvalho I.S (ed.). Palinologia, $3 \mathrm{v}$

Miner E.L. 1935. Paleobotanical examination of Cretaceous and Terciary coals from Montana. The American Midland Naturalist, 16(4):616-625.

Pflug H. 1953. Zur Entstehung und Entwicklung des angiospermiden Pollens in der Erdgeschichte. Palaeontog. Abt. B, Stuttgart, 95(4-5):60-171.
Phipps D. \& Playford G. 1984. Técnicas de laboratório para a extração de palinomorfos de sedimentos. Papers, Departamento de Geologia, Univesity of Queensland, 11, p. 1-23.

Srivastava S.K. 1972. Systematic description of some spores from the Edmonton Formation (Maestrichtian), Alberta, Canada. Palaeontographica, Abteilung B, 139:1-46.

Szatmar P. 1980. The origin of oil deposits: a model based on evaporites. Anais Do XXXI Congresso Brasileiro De Geologia, Camboriú, Santa Catarina, 1, p. 455-499.

Tissot B.P. \& Welte D.H. 1984. Petroleum formation and occurrence. New York, Springer-Verlag, 699 p.

Tyson R.V. 1993. Palynofacies Analysis. The Netherlands, Kluwer Academic Publishers, p. 153-191.

Tyson R.V. 1995. Sedimentary organic matter: organic facies and palynofacies. London, Chapman \& Hall, London, 615 p.

Uesugui N. 1979. Palinologia: técnicas de tratamento de amostras. Boletim Técnico da Petrobras, Rio de Janeiro, 22:229-240.

Wood G.D., Gabriel A.M., Lawson J.C. 1996. Palynological techiniques - processing and microscopy. In: Jansonius J. \& McGregor D.C. (Eds.) Palalynology: principles and applications. Dallas, Texas, American of Stratigraphic Palynologists Foundation, 1, p. 29-50.

Arquivo digital disponível on-line no site wwww.sbgeo.org.br 